\title{
Validation of Unit 1 of the Fukushima Daiichi Nuclear Power Plant During its Accident
}

By Shigenao Maruyama Abstract- Ten years have passed since the Great East Japan Earthquake and the subsequent accident at the Fukushima Daiichi nuclear power plant (NPP) that occurred on March 11, 2011. The earthquake and tsunami caused significant loss of lives and widespread disaster in Japan.

Several reports have been published on the nuclear accident; however, the original data released at the beginning of the accident were written in Japanese, and some of these documents are no longer accessible. Some of the scenarios pertaining to the accident have become standardized theories, and these scenarios may be passed down to future generations with different descriptions, which may not fully describe the actual occurrences. To prevent future nuclear accidents, the accident at Fukushima Daiichi must be properly understood and analyzed.

Keywords: nuclear power plant, accident, isolation condenser, thermodynamic model, fukushima daiichi, great east japan earthquake.

GJRE-F Classification: FOR Code: 290903p

Strictly as per the compliance and regulations of:

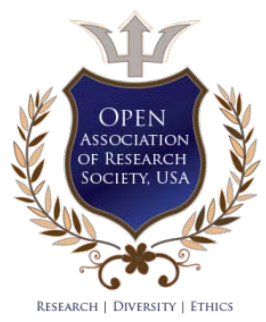

(C) 2021. Shigenao Maruyama. This is a research/review paper, distributed under the terms of the Creative Commons AttributionNoncommercial 3.0 Unported License http://creativecommons.org/licenses/by-nc/3.0/), permitting all non-commercial use, distribution, and reproduction in any medium, provided the original work is properly cited. 


\title{
Validation of Unit 1 of the Fukushima Daiichi Nuclear Power Plant During its Accident
}

\author{
Shigenao Maruyama
}

\begin{abstract}
Ten years have passed since the Great East Japan Earthquake and the subsequent accident at the Fukushima Daiichi nuclear power plant (NPP) that occurred on March 11, 2011. The earthquake and tsunami caused significant loss of lives and widespread disaster in Japan.

Several reports have been published on the nuclear accident; however, the original data released at the beginning of the accident were written in Japanese, and some of these documents are no longer accessible. Some of the scenarios pertaining to the accident have become standardized theories, and these scenarios may be passed down to future generations with different descriptions, which may not fully describe the actual occurrences. To prevent future nuclear accidents, the accident at Fukushima Daiichi must be properly understood and analyzed.

Our research group had been analyzing the accident
\end{abstract} since immediately after its occurrence[2]. To investigate the process of the NPP accidents, Unit 1 of the Fukushima Daiichi NPP was analyzed using data available to the public. A phaseequilibrium thermodynamic model was used in the analysis. We proposed an accident scenario in which the isolation condenser (IC) of Unit 1 may have been working to a certain extent. Moreover, the behavior of the reactor water level meter at the time of the accident was analyzed, and we attempted to reproduce the measurement data of the reactor water level meter and the pressure data measured during the accident. Further more, based on the temperature data of various measuring points and the estimated accident scenario of Unit 1 , we also presented a bold estimation of the locations and times of damages in the reactor pressure vessel (RPV) and primary containment vessel (PCV).

In the present study, the original data reported in the first stage of the accident are examined to clarify the behavior of the ICs, which are generally believed to have been nonfunctional after the tsunami and station blackout. The original data and observation reports verified that the so called "fail-safe" system to close the valves in the ICs did not work properly owing to the shutdown of AC power.

This report assumes that the leakage of the RPV occurred at 20:26 on March 11, 2011 owing to overheat of the nuclear fuel clusters. It is estimated that the leakage of the PCV occurred at 03:30 on March 12. A large break in the RPV occurred at 06:20 and again at 16:00. It is estimated that a large portion of the fuel still remains in the RPV; however, the Tokyo Electric Power Company (TEPCO) estimated that most of the fuel had melted out through the RPV. The present analysis model and accident scenario explain the data measured at the accident and several evidences and witness reports that were collected at the early stage of the accident.

Author: President, National Institute of Technology, Hachinohe College, Hachinohe, Aomori, 039-1192 Japan.

e-mail: shigenao.maruyama@gmail.com
The author attempted to boldly predict the positions and times of vessel ruptures according to the present accident scenario. By examining the temperature data of each part of the reactor obtained after March 23, it is presumed that leakages from the RPV at 10:26, on March 11 , and 6:20, on March 12, occurred at the safety valves, because the significantly high temperature of the steam that discharged through the valveshad destroyed the valve seats.

Keywords: nuclear power plant, accident, isolation condenser, thermodynamic model, fukushima daiichi, great east japan earthquake.

\section{INTRODUCTION}

Then en years have passed since the Great East Japan Earthquake and the subsequent accident at the Fukushima Daiichi nuclear power plant (NPP). Approximately one hour before the occurrence of the earthquake at 14:46 on March 11, 2011, the author had landed at Sendai Airport, Japan, on his way back home from a business trip in the People's Republic of China. Three hours after his arrival, the airport was seriously damaged by the tsunami. Hereinafter, the time described is based on the Japan Standard Time. When the author returned to his home in Sendai city, he encountered the earthquake. His home was damaged by the earthquake.

The earthquake and tsunami caused significant loss of lives and widespread disaster in Japan. More than 15,000 people were killed, and approximately 2,500 people are still reported to be missing [1]

At the Fukushima Daiichi NPP, the earthquake caused damages to the external electric supply required to operate the plant. The subsequent tsunami attacked the NPP, resulting in the loss of the cooling function at the three operating reactor units. Then, accumulation of hydrogen gas occurred in the reactor buildings (R/Bs), resulting in explosions at Units 1 and 3. After the reactor cores of Units 1-3 were damaged, a large amount of radioactive materials were released into the atmospheric environment. The water used for the cooling of the damaged reactor cores was contaminated by radioactive substances, which was then spilled and released into the sea.

The author started exchanging information regarding the NPP on March 15. At that time, the possibility of nuclear fuel core blockage due to seawater injection was being discussed with his acquaintances who were nuclear power professionals. The author estimated the current state of the NPP with the help and 
guidance of nuclear engineering experts and colleagues in academic communities, and disseminated information for early convergence of the accident.

Sendai, where we lived, is located $95 \mathrm{~km}$ north of the Fukushima Daiichi NPP. The thermo-fluid analysis of the NPP was conducted using the electric power and the internet restored relatively quickly after the earthquake. We left half of the gasoline in the tanks of our automobiles for the preparations to evacuate from Sendai if something happened to the NPP.

At the first stage, information was distributed to experts in the field of thermal engineering and to the personnel of the Tokyo Electric Power Company (TEPCO), who were introduced by our colleagues. To disseminate information to the public as soon as possible, the Heat Transfer Control Laboratory of the Institute of Fluid Science, Tohoku University, began distributing heat-and-flow-analysis reports on its website from March 28 [2]. Our laboratory posted 26 reports in the two months from March 28 to May 30, 2011. The total number of reports increased to 48 by March 3 , 2015.

We started to estimate the decay heat of each unit from open data source, and the data were published on the website [HTC Rep. 1.1, 2011/3/28]. Hereinafter, this report[2] is described as [HTC Rep.\#, issued date]. This estimation was corrected, including the operating history of nuclear fuel units [HTC Rep. 1.4, $2011 / 4 / 13]$. At the time of release of the report, our estimation of the decay heat was different from that provided by TEPCO; however, the estimation presented by TEPCO at the later date became almost identical to our data.

We estimated the steam generation rate of each unit and calculated the ruptured area of the primary containment vessels (PCVs) using the plant parameters such as pressure and temperature. The flow rate calculation method utilizing an orifice was applied to the analysis. We reported that the estimated ruptured area on the PCV of Unit 1 was equivalent to a diameter of 9 $\mathrm{cm}$ and that on the suppression chamber $(\mathrm{S} / \mathrm{C})$ of Unit 2 was $20 \mathrm{~cm}$, based on the plant parameters obtained on March 26, 2011 [HTC Rep. 14.2, 2011/5/11]. The ruptured area on the PCV of Unit 3 was estimated to be equivalent to a diameter of $23 \mathrm{~cm}$ based on the plant parameters obtained on May 3. The Japanese governament and TEPCO had not announced that the PCVs of Units 1-3 were ruptured when we released the report on May 11. Then TEPCO announced on May 25 that the PCVs of Units 1 and 2 may have ruptured, and the equivalent diameters of the ruptures on Units 1 and 2 were 7 and $10 \mathrm{~cm}$, respectively.

TEPCO published an estimation of fuel core conditions of Units 1-3 on May 16, 2011 [3], using a large computer simulation code "Modular Accident Analysis Program (MAAP)." It was reported that the operator restarted the isolation condenser (IC) system A
(IC-A) of Unit 1 at 18:18,on March 11, and the ejection of steam from the R/B was confirmed. It was stopped at 18:25, and restarted again at 21:30.

However, TEPCO assumed that the IC of Unit 1 did not work after the station blackout. According to the analysis based on MAAP, the fuel core was damaged 15 $\mathrm{h}$ after the tsunami attack, and all the fuel melted out from the reactor pressure vessel (RPV). TEPCO mentioned that "From the analysis results, fuel core damage started relatively early after the arrival of the tsunami, resulting in damage to the RPV. However, considering the state of the plant estimated from the temperature shown below, the analysis seems to be a a severe consequence" [3]. However, TEPCO maintained the assumption that the IC did not work in their subsequent reports [6], [12].

After this announcement [3], all mass media reported sensationally that the Fukushima Daiichi NPP had melted down. TEPCO also assumed that the IC of Unit 1 was not functional after the station blackout caused by the tsunami. This assumption was followed by a government report [4] stating that "Unit 1 lost its all power supplies shortly after the arrival of the tsunami. The isolation condensers (IC) seemed to have lost its functionality as its isolation valves were fully or almost fully closed by the fail-safe circuits." The International Atomic Energy Agency (IAEA) followed this assumption [5].

However, some key evidences showed that the IC was working. For example, there are original records that the operator restarted IC-A, and steam ejection was observed from the R/B. There are records that the water was injected into the reservoir tank of the IC. As presented in Section 3, the reactor water level indicator shows the correct value when the water level is above the top of active fuel (TAF). The records of the water level meter show that the measured water levels were above the TAF at almost constant values from 21:30 on March 11 to 06:30 on March 12. TEPCO explained in the report on June 20, 2012, that "Therefore, water levels measured after core damage are assumed to be unreliable, while water levels taken via analysis are assumed to be closer to those in reality" [6].

We assumed that the IC was, to a certain extent, functional after the station blackout, and estimated that the breakdown of the RPV occurred considerably later than the estimation presented by TEPCO [HTC Rep.17.2, 2011/5/30]. In the analysis, a simple energy balance [HTC Rep. 1.4, 2011/4/13] was considered. The details are described in a published paper [7]. We constructed a more detailed thermodynamic model to describe the equilibrium state of the RPV and PCV of each unit. We determined that the measured data and original record were well described by the simulation using a thermodynamic model. 
The simulation program used by TEPCO, the MAAP, is a large system; moreover, it requires a relatively long central processing unit (CPU) time to calculate one accident scenario. Conversely, our program is small and was operated in Microsoft Excel. Our simulation can be used to calculate one set of the accident scenarios within a few seconds, and related diagrams are illustrated promptly. This significantly short turnaround time helped us to simulate large number of accident scenarios to fit the measured plant parameters at the time of the accident. In the analysis of Unit 1, we estimated that the IC was functional until around 03:00on March 12, 2011 [HTC Rep.26.1 2013/02/10], [9].

The Atomic Energy Society of Japan estimated that the AC-driven valve of the IC was fully open when the tsunami struck, and questioned the scenario in which the IC did not work at all after the arrival of the tsunami [10].The Nuclear Regulation Authority of Japan (NRA) examined the status of the IC valves at the time of the tsunami attack, and reported that "However, the operating status (open/close) of isolation valves ( $1 \mathrm{~A}$ and $4 \mathrm{~A}$ ) of the IC (system "A") in the PCV is not clear. It is therefore necessary to continue analyses of this issue." [11]. TEPCO followed up the report [6] on unsolved issues in the accident progression and published additional reports [12] - [16]. TEPCO carried out a simulation where the IC was working in the third progress report [14], which was published on May 20, 2015. The report stated that "But in the overall progression of the accident it would be quite likely the there is a minor difference from what actually occurred in Unit1." There was no explanation in the report on why the measured water level showed constant values in the early stages of the accident.

Our accident scenario assumed that the IC was functional until approximately 03:00 on March 12, 2011[HTC Rep.26.1 2013/02/10], [9]. This scenario can explain the measurements of the reactor water level in the early stages of the accident. The reactor water level meter shows different value from reality when the water level is below the TAF. We could reproduce the measured water level data by considering the structure of the reactor water level meter [HTC Rep.32.2, 2014/03/05]. We could also reproduce the data when the water level was lower than the TAF. TEPCO attempted to reproduce the measured data of reactor water levels based on the scenario proposed by TEPCO in the fourth progress report[15], which was presented on December 17, 2015, which is 1.5 years later than our report.

According to the above-mentioned analysis using the thermodynamic model and plant parameters on October 10, 2012, we estimated the location of rupture on the PCV [HTC Rep.25.1, 2012/12/26], [9], and we presumed that the location of the rupture was at the bellows that connects the bottom of the dry well
$(\mathrm{D} / \mathrm{W})$ and the S/C of the PCV. TEPCO examined the interior of the R/B using a robot and determined on May 27, 2014 that water was leaking from the cover of an expansion joint on a vacuum break line; moreover, they estimated that the rupture occurred at the vacuum breaker tube bellows near the bottom of the D/W. This location is considerably close to the location estimated by us on December 26, 2012, which was 1.5 years before the findings of TEPCO [13].

In our analysis [HTC Rep.26.1 2013/02/10], [9], we assumed a very small leakage from a rupture equivalent to a diameter of $0.86 \mathrm{~cm}$ on the RPV of Unit 1. The NRA examined the plant data immediately after the tsunami attack, and reported that "The NRA could not find any plant data indicating the coolant leak from the reactor pressure boundary between the earthquake occurrence and the tsunami arrival" [11].

Based on this finding, we proposed a new accident scenario in which a small leakage occurred at a safety valve (SV) of the RPV at 20:26 on March 11, 2011, and a large leakage occurred at 06:20 on March 12 at another SV [HTC Rep.35.1, 2015/03/03]. The rest of the second scenario was similar to the previous one [9]. We also boldly anticipated the locations of the rupture on the RPV of Unit 1 according to the temperature data after the accident [HTC Rep.32.2, 2014/03/05].

According to our accident scenario and the simulation of Unit 1 [HTC Rep.35.1, 2015/03/03], it was estimated that fuel leakage occurred approximately at 16:00 on March 12, 2011, which was considerably later than the estimation presented by TEPCO [16]. Moreover, we estimated that a significant portion of the fuel remains in the RPV. This estimation was verified by the temperature data of the unit obtained after March 21 [HTC Rep.32.2, 2014/03/05]. TEPCO estimated that all the fuel in the RPV had leaked out and mentioned that "most of the molten fuel generated at the accident fell down to the lower plenum below the reactor pressure vessel" [16].

We performed a similar simulation of Unit 2 using a similar thermodynamic model, and these results are published in [8]. Our accident scenario and simulation results pertaining to Unit 2 show results similar to those of TEPCO [16], which were determined using the large simulation code MAAP. Our result pertaining to Unit 2 shows better agreement with the measured data at the accident than the analysis presented by TEPCO.

We conducted a simulation of Unit 3 using a similar thermodynamic model, and these results are published in [17] and [18]. Our simulation results are different from those of TEPCO. We estimated that the PCV of Unit 3 ruptured at 09:05 on March 13, 2011. We estimated the ruptured area using the plant parameters and decay heat at the accident and determined that the equivalent diameter of the ruptured area was $15 \mathrm{~cm}$ 
[17]. The temperature in the PCV and RPV of Unit 3 is considered to have increased on March 22, because the water injection into the reactor core became significantly small. We estimated that the ruptured area increased to approximately five times larger size than the initial one. It is estimated that the seal on the upper flange of the PCV was damaged on March 22 caused by the hightemperature condition at that time [17].

TEPCO estimated that the decrease in pressure in Unit 3 on the morning of March 13 was due to the fact that the safety relief valve (SRV) was opened, and the vent was operated successfully [6]. On May 2014, water leaks were identified around the expansion joint where the PCV penetrated the main steam pipe $D$ [13]. This indicates that leakage occurred at the bellows of the expansion joint. This finding supports our estimation at that time pertaining to the rupture of the PCV [17]. The NRA confirmed that there was strong contamination on the underside of the shield plug installed on top of the PCV of Unit 3 [19]. This may support the fact that the seal on the upper flange of the PCV was damaged [17].

The author published a book describing the progress of the accident at the Fukushima Daiichi NPP [20]. The events pertaining to the Fukushima Daiichi NPP, Units 1-4, that are dealt with in this book are based on the reports [2] published up to August 2012. The behaviors of the Japanese Prime Minister, Cabinet members, TEPCO executives, and the Director of the Fukushima Daiichi NPP were described based on the facts reported in mass media during and after the accident. Their behavior was described to synchronize with the accident scenarios of Units 1-4 that were presented in our report [2]. Comparing the content of this book with the testimony of the Director of the Government Accident Independent Investigation Commission [21] published after the publication of the book [20], both reports agreed well [HTC Rep.33.1, 2014/6/22]. The words and actions of the members of the office of the Prime Minister and those of the TEPCO executives also agreed well with the reports in this book [20].

The book was written based on our accident scenario before August 2012. However, there are several discrepancies in the analysis of the author [7]. For example, in the first scenario by [7], the author cannot describe why the radiation dose in the $\mathrm{R} / \mathrm{B}$ increased on March 11at 21:51, while the water level at that time was above the TAF. The pressure in the RPV was high when water was injected at 06:20 on March 11 and water could not be injected under the previous scenario.

TEPCO reported that the injected water may not have reached the RPV because the bypass line was constructed in the reactor system. Consequently, based on the findings of the bypass line, the author constructed a new scenario and analyzed the pressure and water level of Unit 1 [HTC Rep.26.2, 2013/03/03] using a thermodynamic model to analyze the accident behavior of Unit 1. The previous accident scenario [9] assumed a small leak in the RPV immediately after the earthquake. The PCV was estimated to rupture at 03:00 on March 12 and the RPV rupture occurred at approximately 06:20 and 16:00 on March 12. The IC was estimated to be functional until approximately 03:00 on March 12. The pressure estimations of the PCV and RPV were in good agreement with the measured data [HTC Rep.26.2, 2013/03/03].

The Atomic Energy Society of Japan reported that the initial leak of the RPV may not have occurred, according to the measured data of the PCV obtained before the arrival of the tsunami [10]. This fact indicates that the scenario [9] that assumes the initial leak of the RPV may not be suitable.

Ten years have passed since the accident at the Fukushima Daiichi NPP. According to TEPCO, the decommissioning process is expected to be completed in another 20-30 years. Several reports have been published on the nuclear accidents, such as [4], [5], [10], [23]. However, the original accident data and records are gradually becoming lost. Some of the original data released at the beginning of the accident are no longer accessible. Certain scenarios of the accident, which is different from what actually happened, have become standardized theories and may be passed down to future generations. To prevent future nuclear accidents, the accident at Fukushima Daiichi must be properly understood and analyzed. Our analysis of the accident [2] may not always be accurate. Even our latest accident analysis may not agree with the actual measured data, or with our own records at the time.

In this study, we verified that if the IC of Unit 1 of the Fukushima Daiichi NPP may have been working normally to a certain extent, and performed an analysis based on that accident scenario. Moreover, the behavior of the reactor water level meter at the time of the accident was analyzed, and an attempt was made to reproduce the measurement data of the reactor water level meter during the accident. Furthermore, based on the temperature data of various measuring points and the estimated accident scenario of Unit 1, we also make a bold estimation of the damaged positions of the RPV and PCV of Unit 1 as well as the times of the damage.

\section{il. Outline of the Accident at Thefukushima Daitchi Nuclear POWER PLANT}

The Great East Japan Earthquake occurred on March 11, 2011 at 14:46. The epicenter was $130 \mathrm{~km}$ east-southeast of the Oga Peninsula in the Pacific Ocean. This earthquake was caused by an energy release at the border of the Pacific tectonic plate and the North American tectonic plate. The earthquake had a 
magnitude of 9.0 , and the tremors lasted for more than two minutes.

Tsunamis following the earthquake struck a wide area of the northeastern coast of Japan. Several waves reached heights of more than $10 \mathrm{~m}$, the largest since the Jogan Earthquake, which occurred in the year of 869, approximately 1150 years ago. The earthquake and tsunami caused significant loss of lives and widespread disaster in Japan. More than 15,000 people were killed, and approximately 2,500 are still reported to be missing [1].

At the Fukushima Daiichi NPP, operated by TEPCO, the earthquake caused damage to all external electric supplies required to operate the plant. The subsequent arrival of the tsunami at the NPP destroyed the emergency power supplies and the operational safety infrastructure on the site. This resulted in the loss of the cooling function at the three operating reactor units.

Consequently, the reactor cores in Units 1, 2, and 3 were overheated owing to the decay heat of the nuclear fuel, and the three PCVs ruptured. Hydrogen gas was released from the RPVs and leaked through the PCVs. The hydrogen gas accumulated in the R/Bs, which resulted in explosions in Units 1 and 3.

Radio nuclides were released from the NPP to the atmosphere and were deposited on land. The radioactive water that is used to cool the plant was released directly into the sea. People within a radius of $20 \mathrm{~km}$ from the NPP site and in other designated areas were evacuated. Those within a radius of $20-30 \mathrm{~km}$ were advised to voluntarily evacuate. Ten years after the accident, many people still live outside the evacuated areas.

Details of the accident before 2015 have been presented in many reports, such as [4], [5], [10], [23]. The interior of the reactors has not yet been revealed. The amount of cooling water that is contaminated by tritium is still increasing, and the storage tanks will be full at the NPP site. The Japanese government is planning to release the contaminated water into the ocean by diluting it with seawater.

An outline of the accidents occurred in Units 16is subsequently presented.

a) Before the Tsunami Attack

The Fukushima Daiichi NPP in Fukushima prefecture consisted of six units of boiling water reactors (BWRs), as listed in Table 1. The BWR units were constructed between 1971 and 1979, and the oldest unit had been in operation for 40 years at the time of the accident. During the operation, several facilities have been replaced, except for the primary structures such as the RPVs, PCVs, and buildings.

When the earthquake occurred, Units 1,2 , and 3 were operating at full power, and Units 4, 5, and 6 were shut down for periodic inspection and maintenance. Unit 4 was stopped for repairing the shroud in the PRV. The spent fuel pool of Unit 4 contained more than 1,300 spent fuel and active fuel assemblies from the reactor. Units 5 and 6 were shut down for periodic inspection, and the fuel assemblies were in the PRVs. 
Table 1: Specifications of the units of the Fukushima Daiichi nuclear power plant and the status at the time of the accident

\begin{tabular}{|c|c|c|c|c|c|c|}
\hline Unit Number & $\mathbf{1}$ & $\mathbf{2}$ & $\mathbf{3}$ & $\mathbf{4}$ & $\mathbf{5}$ & $\mathbf{6}$ \\
\hline Nominal Power (MW) & 460 & 784 & 784 & 784 & 784 & 1,100 \\
\hline Date of Operation Start & $26 / 3 / 1971$ & $18 / 7 / 1974$ & $27 / 3 / 1976$ & $12 / 10 / 1978$ & $18 / 4 / 1978$ & $10 / 24 / 1979$ \\
\hline Type of RPV & BWR-3 & BWR-4 & BWR-4 & BWR-4 & BWR-4 & BWR-5 \\
\hline Type of PCV & Mark I & Mark I & Mark I & Mark I & Mark I & Mark II \\
\hline Main Contractor & GE & GE/Toshiba & Toshiba & Hitachi & Toshiba & GE/Toshiba \\
\hline $\begin{array}{c}\text { Status at the time of } \\
\text { accident }\end{array}$ & $\begin{array}{c}\text { Rated } \\
\text { operation } \\
\text { Rated }\end{array}$ & $\begin{array}{c}\text { Rnder } \\
\text { Rated } \\
\text { operationtenance } \\
\text { for repairing } \\
\text { shroud }\end{array}$ & $\begin{array}{c}\text { Periodic } \\
\text { inspection }\end{array}$ & $\begin{array}{c}\text { Periodic } \\
\text { inspection }\end{array}$ \\
\hline
\end{tabular}

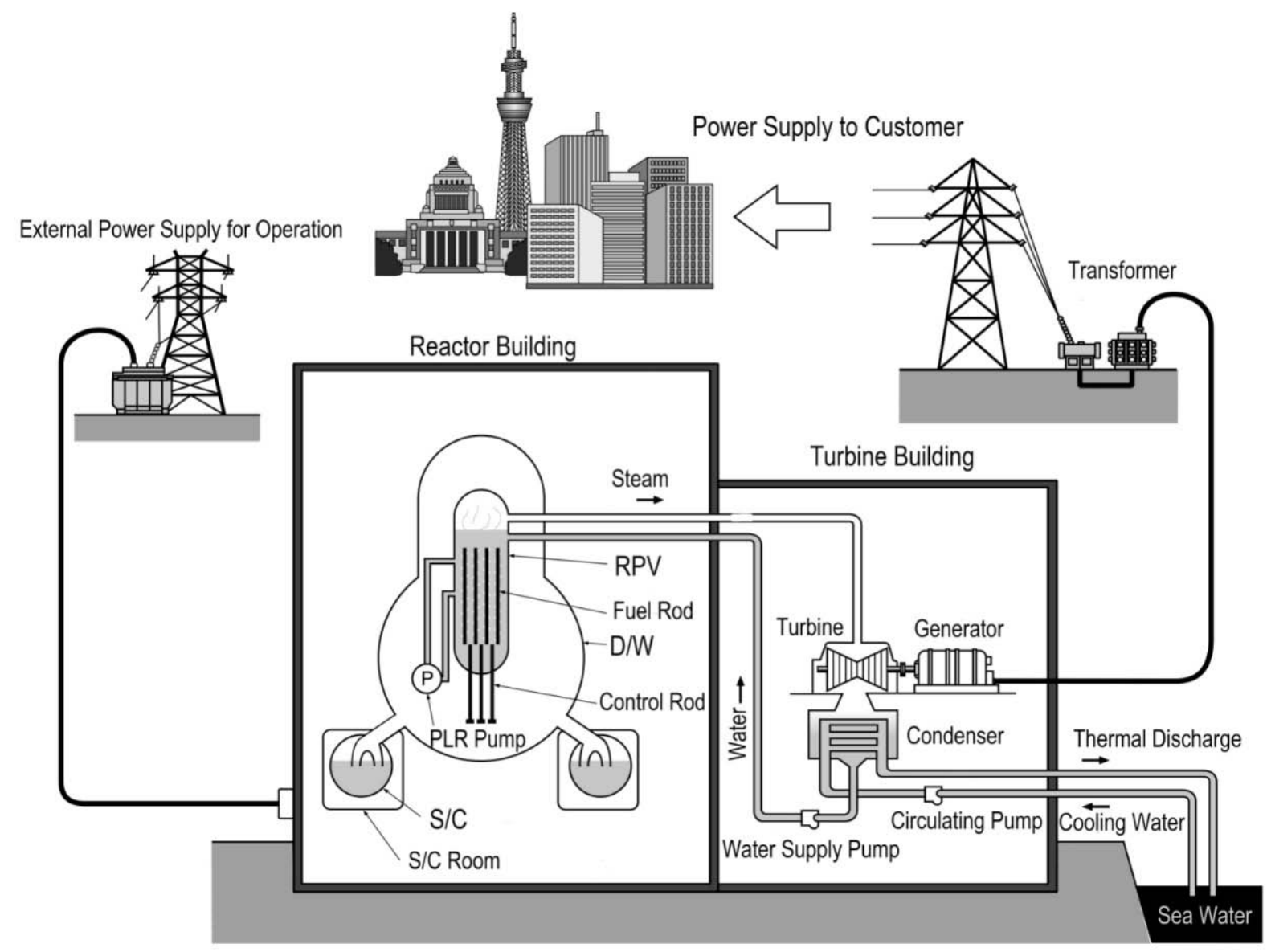

Fig. 1: Overview of the boiling water reactor plant before the tsunami attack [20]

BWRs use a steam cycle loop, as shown schematically in Fig. 1. Coolant water boils in the reactor core at a pressure of approximately $7 \mathrm{MPa}$, and the generated steam is used to drive turbines to generate electricity. After passing through the turbines, the steam is condensed back to water in condenser tubes that are circulated with cold sea water. The water resulting from condensation is pumped back to the reactor as feed water.

In the case of the Fukushima Daiichi NPP, the produced electricity was delivered to the Tokyo area. NPPs require an external power supply to operate the plants. This electric power was supplied by the Tohoku
Electric Power Company because the location of the Fukushima Daiichi NPP is within the jurisdiction of this company, which is different from the Tokyo Electric Power Company (TEPCO). This external electric power is used to cool down the fuel core after the NPP is shutdown.

Units 1-4 were built $10 \mathrm{~m}$ above sea level, and Units 5 and 6 were on the ground level, $13 \mathrm{~m}$ above sea level. Units 1 and 2 were controlled by a main control room, and Units 3 and 4 were controlled by another main control room. A seismically isolated building was constructed for an emergency accident of the NPP one year before the accident. This building had emergency 
electric generators and air cleaners to prevent the entry of radio active materials into the building. A local emergency headquarter was set up in the building in the occurrence of an accident.

When the Great East Japan Earthquake of magnitude 9 occurred, the recorded maximum acceleration at the Fukushima Daiichi NPP was 550 gal. The operating reactors of Units 1,2, and 3 were shut down automatically and the fission reaction in the reactor cores was stopped. However, these reactors had to be cooled because decay heat was generated inside the reactor cores. The earthquake caused damage to the switchboard equipment, and the external AC power supply from Tohoku Electric Company to the plant was shut down. The emergency diesel generators automatically started to restore the AC power in all six units. The ICs in Unit 1 started automatically to cool the reactor. The operators manually activated the reactor core isolation cooling systems (RCICs) in Units 2 and 3.

\section{b) After the Tsunami Attack}

The initial tsunami waves arrived at the NPP approximately 40 min after the earthquake. The site was protected from the first wave by a barrier seawall, which was designed to protect the land against a tsunami of $5.5 \mathrm{~m}$ height. The second tsunami wave arrived at 15:36. It was estimated to be more than $14.5 \mathrm{~m}$ high. This tsunami attacked the NPP and destroyed the emergency diesel generators and DC batteries. A station blackout was declared for Units 1-5 at 15:42. The residual heat removal system (RHR) did not function because of the station blackout.

At the time of the tsunami attack, the situation at each unit was as described subsequently.
Unit 1: The emergency diesel generators were damaged, and the AC power was lost. The DC batteries became nonfunctional owing to the invasion of seawater. IC system B (IC-B) was manually stopped before the tsunami attack, and IC-A was manually operated before the arrival of the tsunami. When the tsunami hit the NPP, the valve of IC-A was closed, and the IC was not activated.

Unit 2: The emergency diesel generators were damaged, and the AC power was lost. The DC batteries became nonfunctional owing to the invasion of seawater. The RCIC was started just after the arrival of the tsunami. Fortunately, the RCIC worked until 13:00 on March 14, without the DC power.

Unit 3: The emergency diesel generators were damaged, and the AC power was lost. The DC batteries survived against the tsunami attack. Using the DC power, the emergency core cooling systems were operated until 02:42 on March 12.

Unit 4: The fuel assemblies from the reactor fuel were stored in the spent fuel pool, and the fuel was generating decay heat. The cooling function of the spent fuel pool was lost owing to the loss of the external power supply and emergency generators.

Units 5 and 6: The batteries were not damaged, and DC power was available. An air-cooled emergency diesel generator in Unit 6 survived the tsunami attack. Using the AC power from this operational generator, the operators managed to cool the decay heat in the reactor cores. Finally, the reactors stabilized.

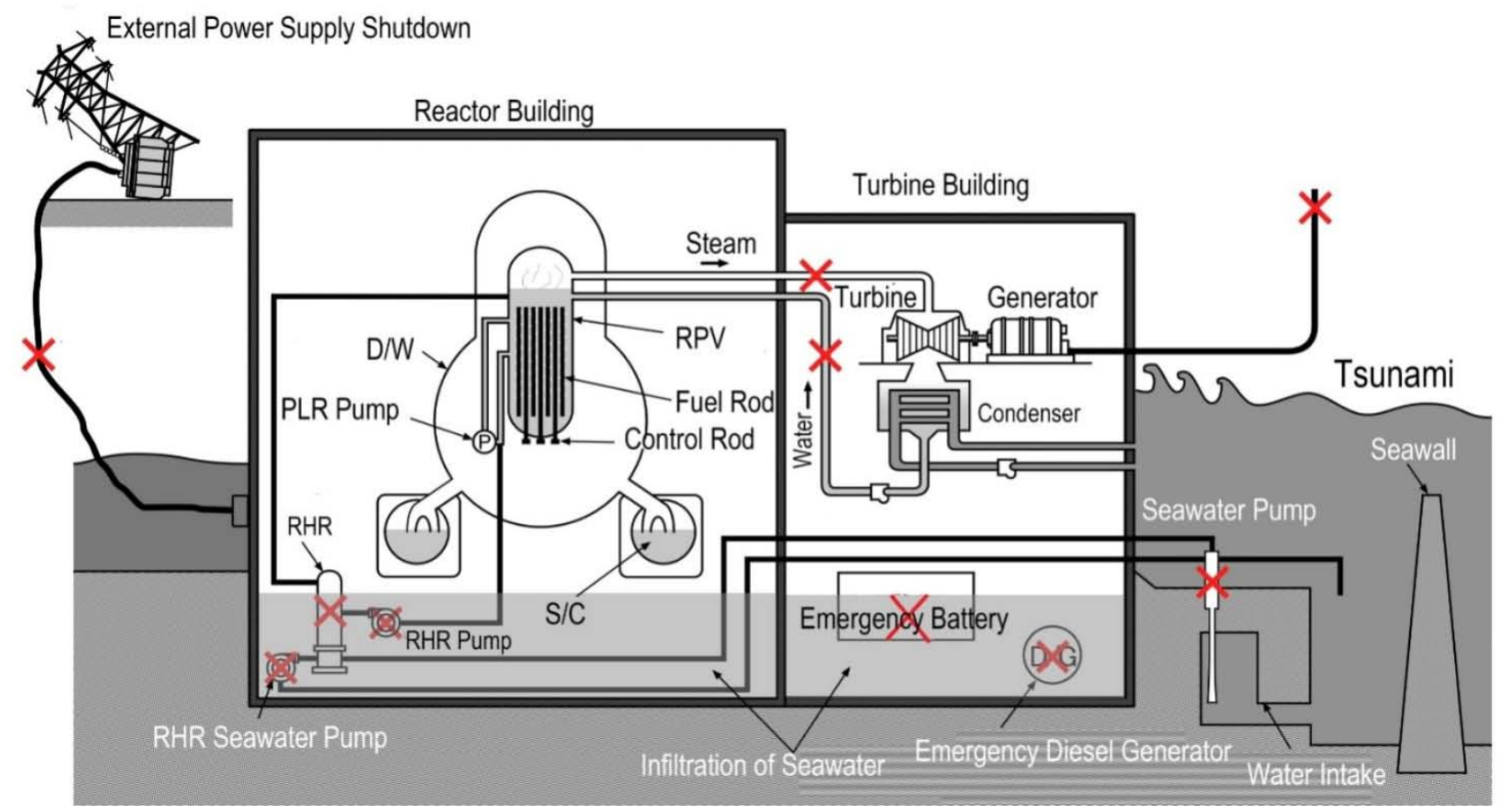

Fig. 2: Situation at the nuclear power plant (NPP) after the arrival of the tsunami at 16:00 on March 11, 2011[20] 
c) Explosion of the Reactor Buildings of Units 1 and 3

Unit 1: The cooling function of Unit 1 was lost on the night of March 11, and the PCV exceeded its maximum design pressure at 23:50 on March 11. The radiation level at the main gate of the NPP increased at 04:00 on March 12, and TEPCO attempted to inject water into Unit 1.An explosion occurred in the R/B of Unit 1 at 15:36. The explosion damaged the R/B; however, the PCV was not damaged. This explosion was caused by the accumulation of hydrogen gas that was generated by the chemical reaction between the high-temperature zirconium and water vapor in the fuel core.

Unit 3: Immediately after the tsunami attack, the DC batteries of Unit 3 were functional, even though the emergency AC generators were nonfunctional. Hence, the RCIC of Unit 3 was working at that time. The RCIC became in operative at 11:36 on March 12; then, the high-pressure coolant injection system ( $\mathrm{HPCl}$ ) started automatically owing to the low water level in the RPV. The HPCl was stopped at 02:42 on March 13. Fresh water was injected into the RPV at 09:25, and the seawater was injected at 13:25 by venting the internal gas into the environment. An explosion occurred at 11:01 on March 14 in the R/B. This explosion was caused by the accumulated hydrogen gas that was generated by a chemical reaction between the hightemperature zirconium and water vapor in the fuel core of Unit 3.

d) Rupture of the PCV of Unit 2 and the Explosion of the Reactor Building of Unit 4

Unit 2: According to the report of TEPCO [6], the RCIC repeated an automatic stop function owing to water level in the RPV and manual restarting was performed before the tsunami attack. The RCIC was stopped automatically at 15:28, and the tsunami attacked Unit 2 at approximately 15:35. The operator restarted the RCIC manually at 15:39. Owing to the tsunami attack, the emergency diesel AC generators and DC batteries in Unit 2 became nonfunctional at approximately15:41. The $\mathrm{RCIC}$ was working, and the appropriate valves were open when the blackout occurred.

Fortunately, the RCIC of Unit 2 was working without electricity. It was presumed that the turbine and pump powers were balanced and the RCIC continued working for almost $70 \mathrm{~h}$ without any control after the blackout. Finally, the RCIC became nonfunctional at 10:30 on March 14.

The seawater injection into the RPV started at 19:54 on March 14, and the pressure in the RPV was reduced by manually opening the SRV. Owing to the release of the internal gases of the RPV into the PCV, the pressure in the PCV increased; however, the pressure in the PCV could not be reduced because the depressurization by venting was unsuccessful.

Owing to the pressure increase in the PCV, the PCV ruptured at approximately 06:00-08:00 on March
15, and a large amount of radioactive materials was released into the environment. White smoke or steam was observed near the fifth floor in the R/B of Unit 2. The radiation dose measured at the main gate at approximately 09:00 was $12 \mathrm{mSv} / \mathrm{h}$, which was the highest since the beginning of the accident.

Unit 4: Vibrations due to the explosion were reported at 06:14 on March 15 by the operators in the main control room of Units $1 / 2$. These vibrations were caused by the explosion of the R/B of Unit 4 at 06:12 [6]. The evacuating personnel reported that the upper part of the R/B blew out at approximately 06:00 on March 15.

It was presumed that this explosion was caused by the hydrogen gas released from Unit 3. The process of venting the internal gases and steam was repeated in Unit 3 after its explosion at 11:01 on March 14. This venting process was conducted using the standing gas treatment system (STGS) line and the exhaust stack. Units 3 and 4 used the same exhaust stack, and the STGS lines of Units 3 and 4 were connected. TEPCO estimated that a part of the produced hydrogen gas in Unit 3 was accumulated in the R/B of Unit 4, and the hydrogen gas exploded.

The spent fuel pool on the fifth floor of the R/B of Unit 4 contained more than 1,300 fuel assemblies, including the active fuel assemblies from the reactor. These fuel assemblies from the reactor core produced a large amount of decay heat. The cooling function of the spent fuel pool was lost owing to the blackout of Unit 4.

The US government was concerned with the blackout and explosion of Unit 4, and the damage to the spent nuclear fuel pool, which could result in a large discharge of radioactive materials. Consequently, the US government issued an evacuation advisory to Americans staying within a radius of 50 miles from the Fukushima Daiichi NPP on March 16. However, it was confirmed that water existed in the pool; moreover, water was filled stably into the pool using concrete pump vehicles from March 22.

\section{e) Release of Radioactive Materials}

After the reactor cores of Units 1-3 were damaged, water was injected into the RPVs. The evaporated steam and radioactive materials were released into the atmospheric environment. Immediately after the explosions of the R/Bs, seawater was injected, followed by the injection of fresh water from March 25 . The spilled water that was contaminated by the radioactive materials was released into the sea through the trench, which is an underground tunnel for storing pipelines and cables.

The IAEA [5] reported that the released mean total activity of ${ }^{131}$ I (half-life time is 8 days) was $100-400$ $\mathrm{PBq}$, and that of ${ }^{137} \mathrm{Cs}$ (half-life time is 30 years) was approximately 7-20 PBq. The unit, 1peta-becquerel, equals $10^{15} \mathrm{~Bq}$. The release of radioactive materials owing to the accident was estimated to be 
approximately one-tenth of the radioactive materials released owing to the accident in 1986 at the Chernobyl NPP. The direct release of ${ }^{131}$ I into the sea was estimated to be $10-20 \mathrm{PBq}$, and that of ${ }^{137} \mathrm{Cs}$ was approximately 1-6 PBq.

TEPCO constructed a contaminated water cycle, as shown in Fig. 3. The spilled-out contaminated water from the broken RPVs was pumped up and stored in a temporary storage tank. The oil was removed from the contaminated water, and cesium was removed using a facility called Simplified Active Water Retrieve and Recovery System; further, strontium and other radioactive materials were removed using an Advanced Liquid Processing System. The decontamination equipment cannot remove tritium because hydrogen and tritium are the same chemically and physically. The decontaminated water was desalted using a nano-pore film. Purified clean water was injected into the highly contaminated RPVs to cool the decay heat.

This water cycle is basically maintained at present. Water in the outside soil flows into the basement of the reactor and turbine buildings, and it is stored in the tanks constructed on the NPP site. The cooling water contaminated with tritium is increasing, and storage tanks are full on the NPP site. The Japanese government is planning to release the contaminated water into the ocean by diluting it with seawater.

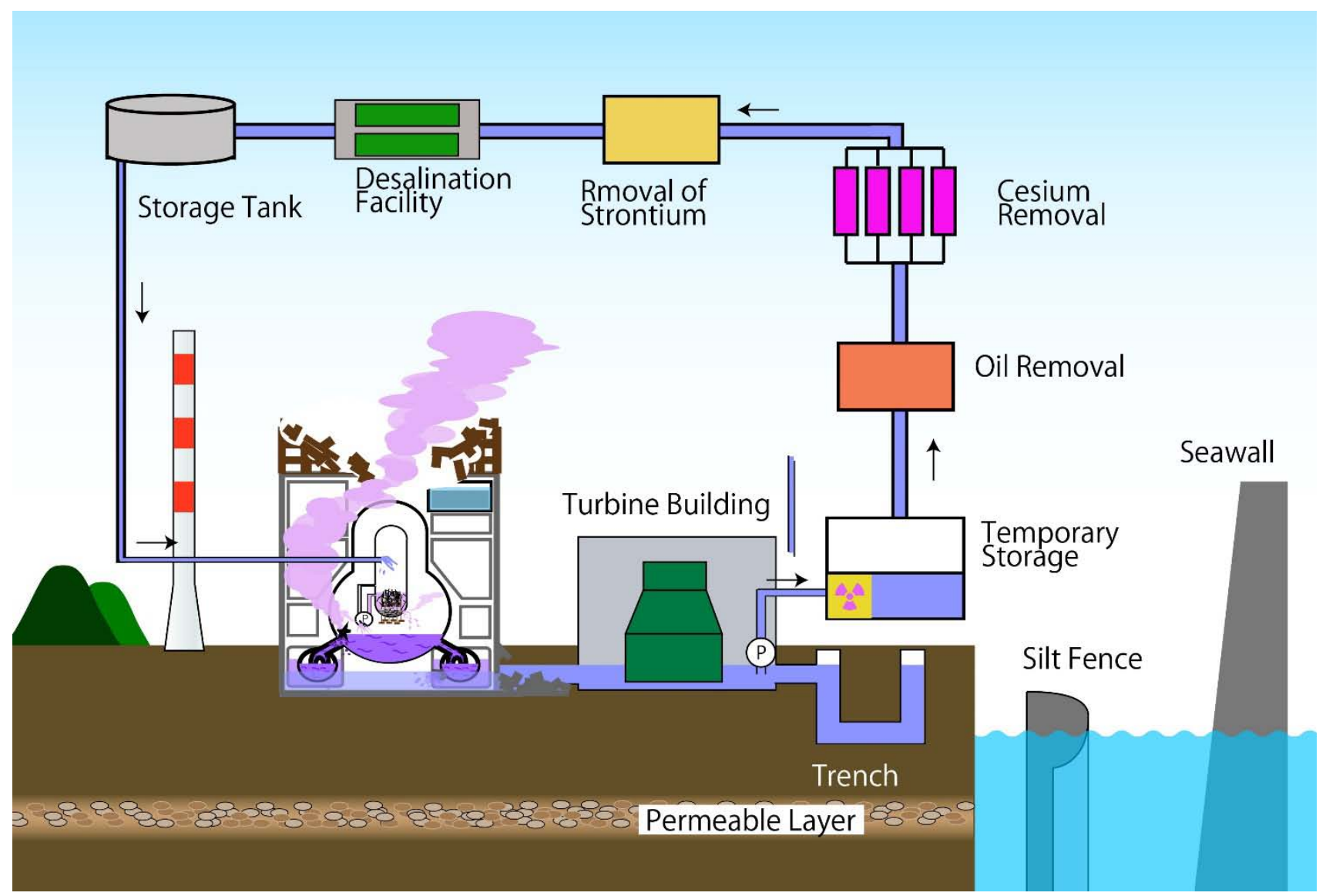

Fig. 3: Status of the contaminated water cycle, as of August 2011 [24]

During the Fukushima Daiichi NPP accident, no one was killed by acute radiation syndrome, which is caused by direct irradiation from the radioactive materials released owing the accident. It was reported that 28 emergency workers were killed because of the acute radiation syndrome within four months of the Chernobyl accident in 1986.

Many people were killed during the evacuation process. For example, 388 elderly patients in a hospital within a $20 \mathrm{~km}$ radius were evacuated in normal buses after the explosion of Unit 3. They are transported without proper care, and 21 died during and after the evacuation process. Many other people died after the evacuation owing to mental and physical diseases caused by the evacuation. 


\section{ili. Behavior of Isolation Condensers (ics) of Unit 1 During the Accident}

a) Structure of ICs and Reactor Water Level Meter

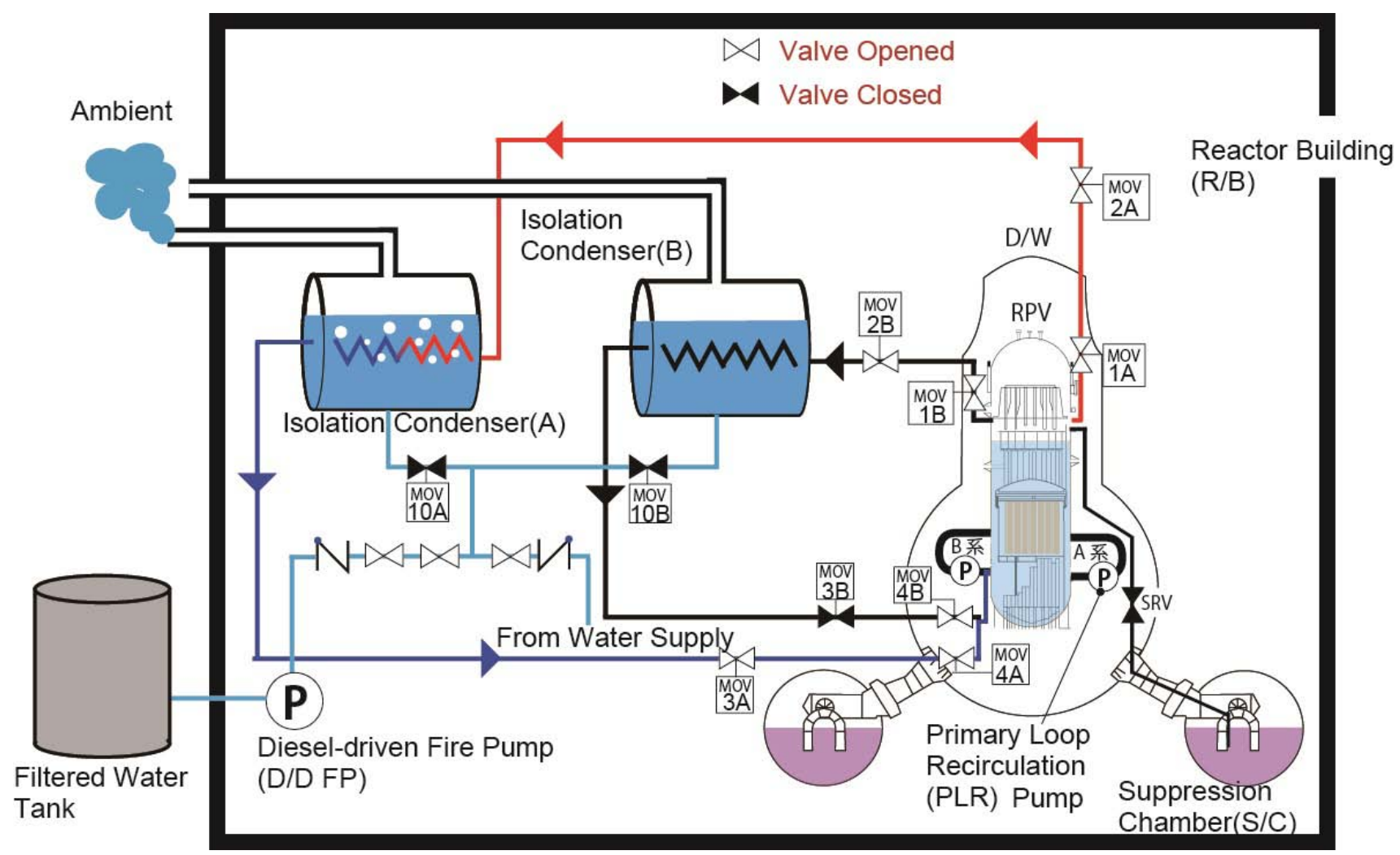

Fig. 4: Structure of isolation condensers (ICs) and main steam safety release valves (SRVs), and their arrangement in Unit 1 [9]

Unit 1 of the Fukushima Daiichi NPP was the oldest unit in the NPP and was equipped with ICs for emergency cooling. When a reactor scrams, and the fission reaction stops, the $\mathrm{IC}$ cools the decay heat of the fuel cores. The steam released by the decay heat enters the heat transfer tube installed in the $\mathrm{IC}$, and it is condensed by the water in the IC reservoir tank. The condensed water returns to the reactor. The water in the $\mathrm{IC}$ reservoir tank evaporates, and steam is released from the R/B. The cooling process by the IC can function without external electric power.

Figure 4 shows the emergency cooling system using the ICs and their valve positions. Four valves connecting each IC and the RPV are attached to IC-A and IC-B. These valves are motor-operated valves (MOVs), which hold their position "as it is" when the electric power supply stops. MOV- 1 and MOV-4 are AC motor-driven valves, and MOV-2 and MOV-3 are DC motor-driven valves. The positions of the valves are shown in Fig. 4. MOV-3A and MOV-3B, of systems A and $B$, respectively, are closed and the other valves are open when the reactor is in operation. The reservoir tank of the IC is connected to a filtered water tank. The water is supplied by a diesel-driven fire pump (D/D FP) when the IC is operated for a long time.
When the reactor was stopped by a scram due to the earthquake, the ICs started automatically. The operator stopped system B, i.e., the operator closed MOV-3B. Moreover, system A was intermittingly operated to maintain the temperature decrease of the reactor within $55^{\circ} \mathrm{C} / \mathrm{h}\left(100^{\circ} \mathrm{F} / \mathrm{h}\right)$. Just before the tsunami attack at 15:36, MOV-3A was closed at 15:34 by the operator. 


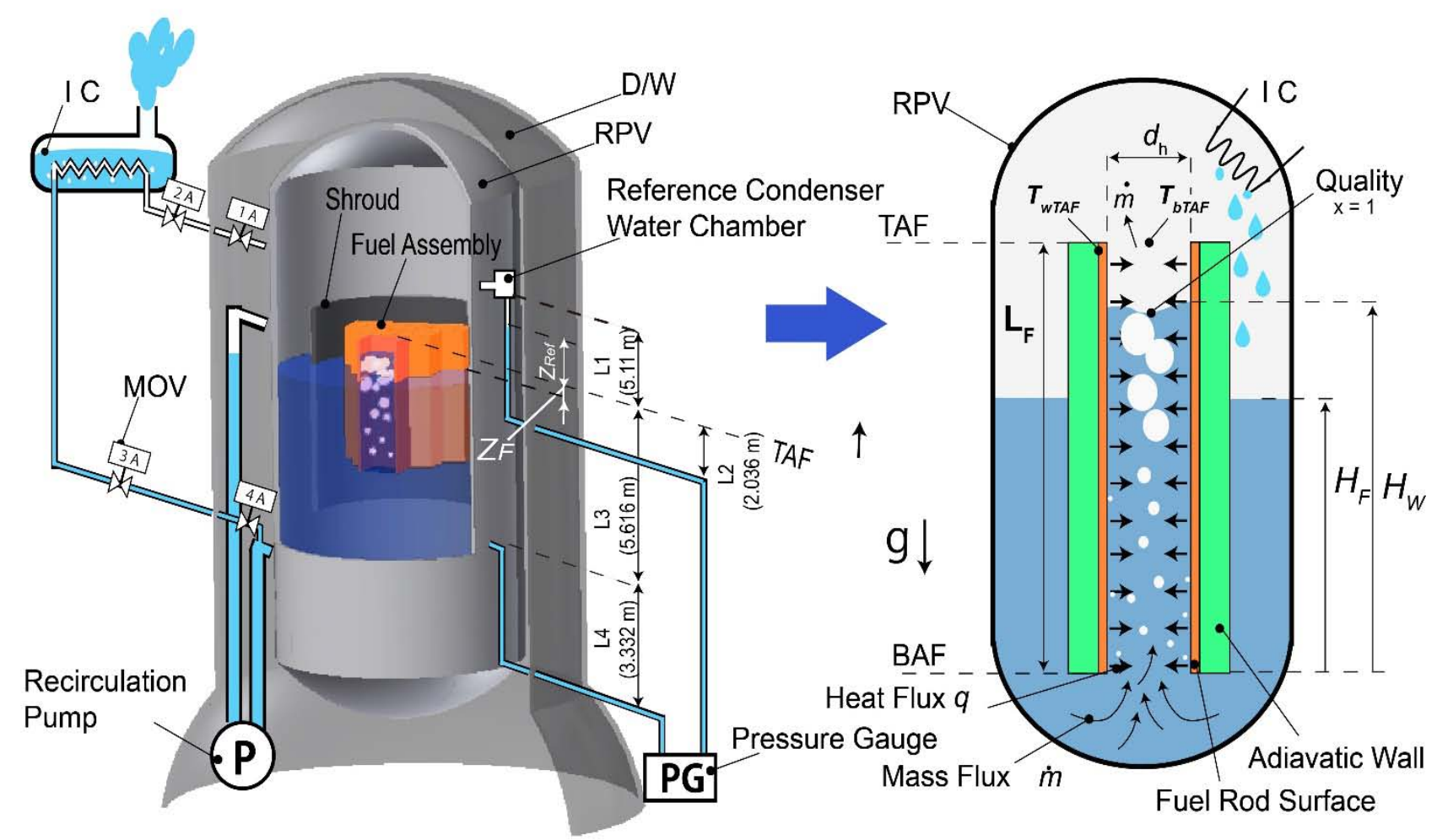

Fig. 5: Structure of reactor water level meter and boiling heat transfer model of fuel assemblies

As discussed in Section 3.3, the reactor water level meters showed constant values in the early stages of the accident. This measurement data is important for verifying the behavior of the IC. Figure 5 shows a schematic of the reactor water level meter. The water level of a BWR is measured by the water head difference between the water level of the reactor fuel region $Z_{F}$ and the water level $Z_{\text {Ref }}$ of the reference condensing water chamber, which is placed outside the RPV. The water level of the reactor fuel region $Z_{F}$ is expressed as $Z_{F}=$ $H_{F}-L_{F}$ in Fig. 5, when $Z_{F}$ is lower than the TAF. The reference condensing water chamber is connected to the PRV by a tube. The difference in water heads between $Z_{F}$ and $Z_{\text {Ref }}$ is measured by a pressure gauge placed outside the PCV.

The temperature of the reference condensing water chamber is marginally lower than that of the RPV. Hence, the saturated water vapor in the RPV flows in the chamber and condenses to water in the chamber. The condensed water in the chamber flows back to the RPV. Hence, the water level of the reference $Z_{\text {Ref }}$ is equal to $L_{1}$. Accordingly, the water level meter shows a constant water head when the water level of the RPV is higher than the TAF. When the water level becomes lower than the TAF, high-temperature unsaturated vapor dries the chamber, and the water level $Z_{\text {Ref }}$ in the pipe connected to the reference condensing water chamber falls from the reference height $L_{1}$. Accordingly, the measured apparent water level is displayed higher than the actual one $Z_{F}$. b) Response of TEPCO after the Tsunami Attack

TEPCO released a report [25] that described the actions undertaken by TEPCO based on the plant data measured immediately after the accident. Although this report [25] was published on June 18, 2011, later than the report on May 23 [3], it is believed that the report describes the situation of the NPP immediately after the accident. The facts related to the ICs are summarized as follows:

March 11, 2011

14:46: The Great East Japan Earthquake occurred. An automatic reactor scram occurred.

14:47: Automatic startup of emergency diesel generators occurred.

14:52: The ICs of Unit 1 were confirmed to have started automatically.

Because the reactor water level was at the normal level, it was decided that the $\mathrm{HPCl}$ will be activated when the reactor water level drops, and the reactor pressure will be controlled by the IC.

Around 15:03: The reactor pressure in Unit 1 dropped too fast to comply with the reactor cooling-temperature drop rate of $55{ }^{\circ} \mathrm{C} / \mathrm{h}$ that is specified in the safety regulations, and the return piping isolation valves of the IC (MO-3A and MO-3B) were closed. The other valves were kept open, and in the normal standby state. It was judged that one IC series would be sufficient to control the reactor pressure to approximately 6-7 $\mathrm{MPa}$; consequently, it was decided to control the reactor 
pressure using system A. Moreover, the reactor pressure control was operated by opening and closing the return piping isolation valve (MO-3A).

15:35: Second wave of the tsunami arrived.

15:37: Loss of all AC power and station blackout occurred

We checked the status of the IC and HPCl for Unit 1 as they were operational equipment with DC power. It was confirmed that the valve open/close indication of IC was not visible.

Around 15:50: The DC power supply for measurement was lost, and the reactor water level became unknown.

We started collecting batteries and cables from companies in the NPP. We brought them to the central control room, checked the drawings, and started connecting them to the instrument panel in the Unit 1/2 central control room.

In the central control room, the indicator lamps of the return piping isolation valve (MO-3A) and supply piping isolation valve (MO-2A) were observed to be $\mathrm{ON}$, probably owing to the temporary restoration of the $\mathrm{DC}$

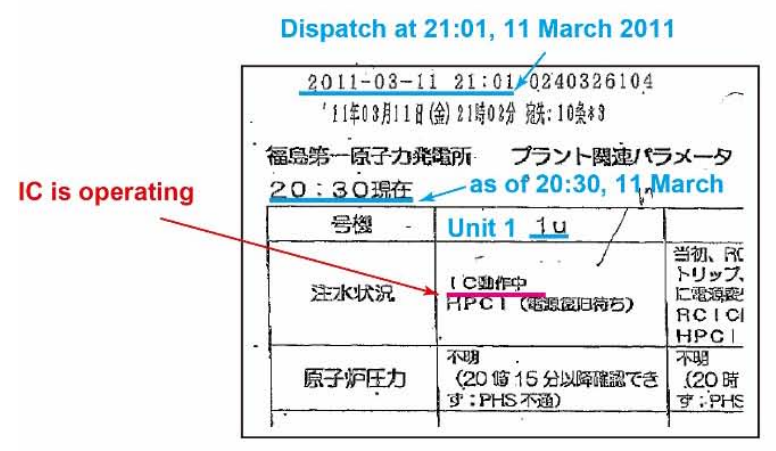

Dispatch at 00:56, 12 March 2011

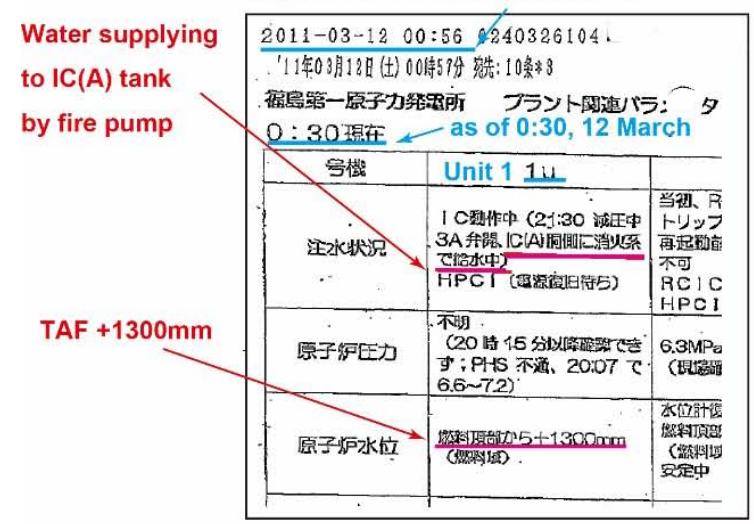

power supply. When we checked the status, we determined that these valves were closed.

18:18: The return piping isolation valve $(\mathrm{MO}-3 \mathrm{~A})$ and supply piping isolation valve $(\mathrm{MO}-2 \mathrm{~A})$ of the $\mathrm{IC}$ were opened, and steam generation was confirmed.

18:25: The return pipe isolation valve $(\mathrm{MO}-3 \mathrm{~A})$ was closed.

21:19: The water level in Unit 1 was determined as TAF $+200 \mathrm{~mm}$.

21:30: The return piping isolation valve $(\mathrm{MO}-3 \mathrm{~A})$ was opened, and steam generation was confirmed.

21:51: Entry to the R/B was prohibited owing to the increased radiation levels in the building.

22:00: It was confirmed that the water level was TAF $+550 \mathrm{~mm}$.

March 12, 2011

02:30: The pressure of D/W reached $840 \mathrm{kPa}(\mathrm{Abs})$.

04:55: It was confirmed that the radiation dose was increased in the NPP from $0.069 \mu \mathrm{Sv} / \mathrm{h}(04: 00)$ to 0.59 $\mu \mathrm{Sv} / \mathrm{h}(04: 23)$ near the main gate.

Dispatch at 22:19, 11 March 2011

\begin{tabular}{|c|c|c|c|}
\hline \multicolumn{3}{|c|}{ 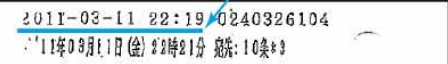 } & \multirow{3}{*}{$\begin{array}{l}\text { IC is operating } \\
(21: 30 \text { Pressure decreasing, }\end{array}$} \\
\hline \multicolumn{3}{|c|}{ 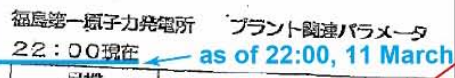 } & \\
\hline 믁㩯 & Unit $11 \mathrm{u}$ & & \\
\hline 注水將织 & 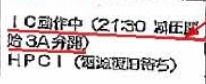 & 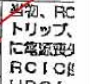 & Valve 3A Open) \\
\hline 原子綟开力 & 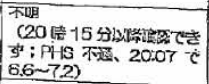 & 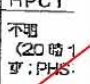 & $\begin{array}{l}\text { Reactor water level } \\
\text { TAF }+550 \mathrm{~mm}\end{array}$ \\
\hline 原子沪水㕸 & 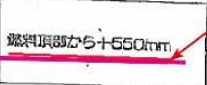 & 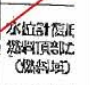 & \\
\hline
\end{tabular}

Incomming at 4:36, 12 March 2011

\begin{tabular}{|c|c|c|c|}
\hline \multicolumn{3}{|c|}{ 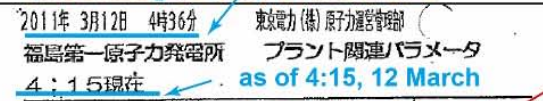 } & \multirow{2}{*}{$\begin{array}{l}\text { Water supply to } \\
\text { IC(A) tank }\end{array}$} \\
\hline 㞻槛: & Unit 114 & & \\
\hline 海水爿㫛。 & 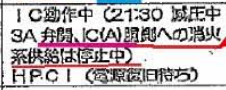 & 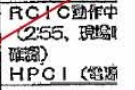 & is suspending \\
\hline 原子炉正力 & 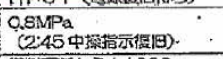 & 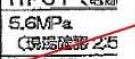 & $\mathrm{mm}$ \\
\hline 原子吅水位 & 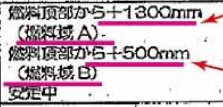 & 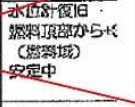 & TAF $+500 \mathrm{~mm}$ \\
\hline $\begin{array}{c}\text { D/W Pressure } \\
\text { D } / \text { W I }\end{array}$ & $840 \mathrm{kPa}$ & gompa & (Fuel region B) \\
\hline 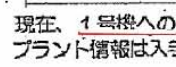 & & & - $840 \mathrm{kPa}$ \\
\hline
\end{tabular}

Fig. 6: Behavior of IC system A according to the original records of the plant parameters during the accident. The records were extracted from the original list of plant parameters at the time of the accident (released on June 24, 2011) [26].

c) Original Records of Accident and Plant Parameters

The Nuclear and Industrial Safety Agency (NISA) released documents from TEPCO [26]. In this document, original faxes and plant parameters at the time of the accident were included. We examined the large amount of available original data to investigate the accident. 
As shown in Fig. 6, there is a description stating "Water supply to IC (A) tank by fire pump" (water is supplying to the resaviour tank of IC(A) by a dieseldriven fire pump(D/D FP) system) in the original plant parameter at 00:30 on March 12. Thus, the D/D FP system shown in Fig. 4 may have been supplying cooling water to IC-A at this time. If that is the case, it is highly likely that the water supply stopped before 04:15, because "Water supply to IC(A) tank is suspending" was reported at 04:15.It is possible that the water supply continued until the IC was shut down.

TEPCO considered that the IC was not functional [6], because the so called "fail-safe system" worked after the tsunami attack and all valves connecting the RPV and ICs were shut down. TEPCO measured the amount of water in the IC tank long after the accident [3], and there was sufficient water in the tank. The water volume in the reservoir tanks of ICs measured after the accident was in good agreement with the volume of consumed water that was calculated based on the nonfunctional IC. According to the description in Fig. 6, the amount of cooling water in the tank of IC-A based on the assumption by TEPCO that there was no water supply may have been a coincidence.

In the original list of plant parameters, recorded at $21: 30$, there is a record that "The IC is in operation."
This implies that the IC was in operation at the latest at $20: 30$. There is another record in the list of plant parameters recorded at 22:30 that the IC was in operation ("pressure decreased at 21:30. 3A valve opened"). These two records contradict each other. From the fact that the IC was in operation as shown in Fig. 6, and from the eyewitness testimony confirming that it is highly likely that the IC was operating as initially reported in the accident.

The Investigation Committee of the Government of Japan [4] concluded that the ICs did not function after the tsunami attack, because as soon as the DC power was off, the AC MOVs were closed by the "failsafe" sequence. The Committee also accused that the Director of the Fukushima Daiichi NPP was not aware that the IC had stopped, and that this misunderstanding caused the accident to be more serious. It would have been difficult to believe that the IC was shut down when the central control room reported that the IC was operating and there were various eyewitness reports. In addition, the Committee stated that there was no water supply to the IC. This contradicts the records at the time of the accident, as shown in Fig.6.

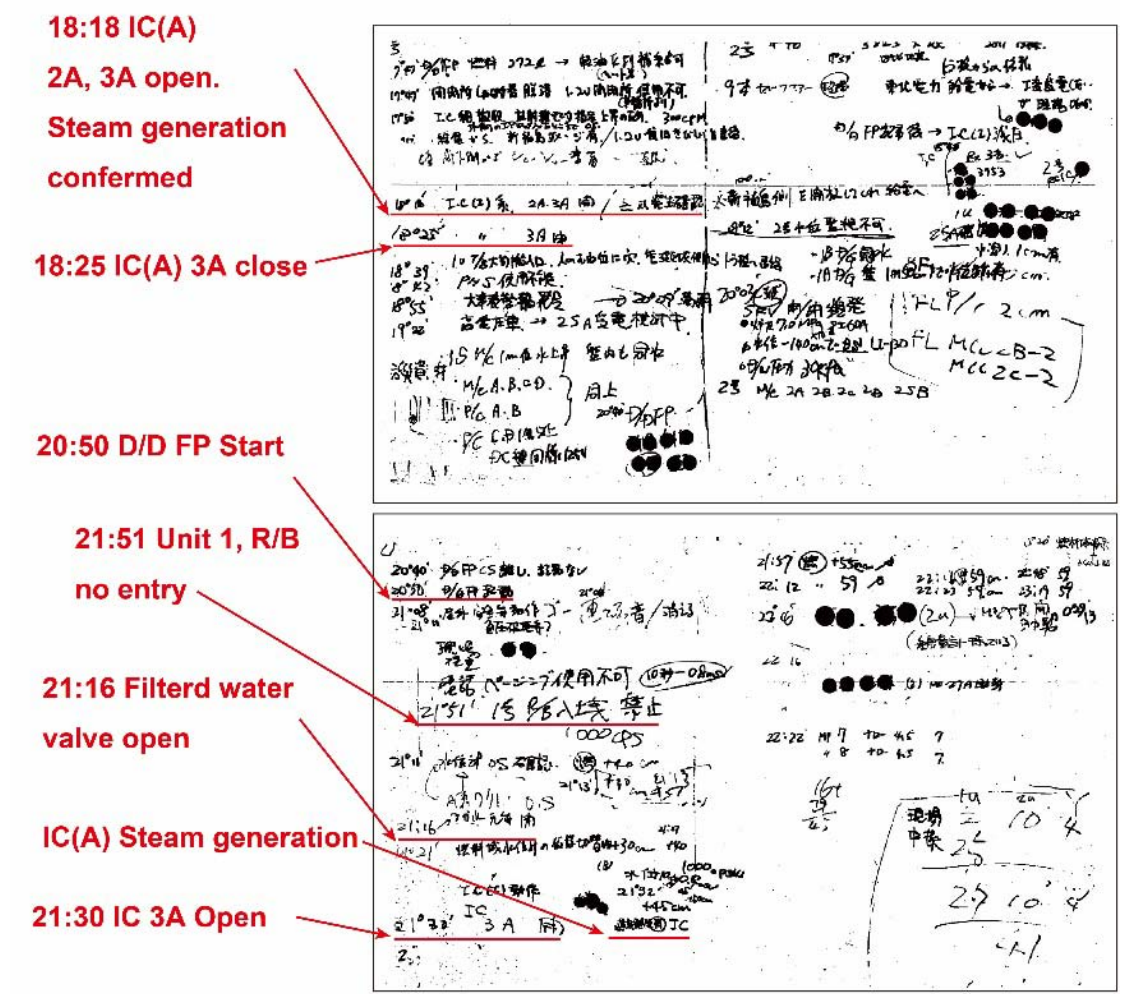

Fig. 7: Records of the white board in the central control room at the time of the accident. The white board records at the time of the accident were taken from the operation logbook reported by Tokyo Electric Power Company (TEPCO) on May 16, 2011 [26]. 
Figure 7 shows the white board record in the central control room at the time of the accident. According to the record of IC operations, records indicated "20:50 D/D FP start" and "21:16 filtered water valve open" (the main valve for filtered water for cooking the IC was opened at 21:16). Because supplying filtered water by the D/D FP is the standard water supplies to the IC tank, as shown in Fig. 4, it implies that the operators supplied water to the IC tank at this point. This record does not contradict the $\mathrm{IC}$ water supply record in Fig. 6. The Investigation Committee of the Government of Japan [4] ignored all these records. These descriptions in the white board imply that the restart of the IC was before 21:30, because it is unlikely that water is supplied before the IC starts. Accordingly we assumed that the IC was restarted at 20:30.

At the initial stages of the accident, TEPCO reported [25] that the IC was operational after the tsunami attack at 15:36 on March 11, 2011. And steam ejection was observed from the IC when the IC was restarted at 18:18, and 21:30. However, TEPCO assumed that the IC did not function after the tsunami attack in their report [6]. They ignored the observed steam ejection at 18:18 and 21:30. They also ignored that water was supplied to the reservoir tank of IC-A at 21:35.

The record on the white board indicates that "18:18 IC(A) 2A, 3A open. Steam genereation confirmed" (IC(A) MOV-2A and 3A was opened at 18:18, and steam generation was confirmed),"18:25 IC(A) 3A closed" (IC(A) MOV-3A was closed at 18:25) and "21:30 IC(A) 3A open" (IC(A) MOV-3A was opened at 21:30), and "IC(A) steam steam generation." These records are in accordance with the actions of TEPCO immediately after the accident [25], as described in the previous section b.

According to a recent investigation [19], AC power system A became nonfunctional at 15:36:59 on March 11, 2011, and the other line was nonfunctional; a few minutes later. As shown in the previous section $b$, the DC power was lost at approximately 15:50. The ACoperated valve requires approximately $20 \mathrm{~s}$ to closefully, and the DC-operated valve requires approximately $15 \mathrm{~s}$. The fail-safe system is activated when the DC power is lost, and the AC-driven motor valves, MOV-1A, MOV-4A, MOV-1B, and MOV-4B, are automatically closed. It is unlikely that the AC-driven motor valves,MOV-1A and MOV-4A, wereclosed by the fail-safe system.

Long after the accident, TEPCO investigated the valve positions of MOV-1A and MOV-4A to determine if they were fully closed. The AC power in the NPP was recovered between March 20 and March 24, 2011. It is possible that these AC MOVs were closed by the failsafe signal when the $A C$ power was recovered. As shown in the previous section $b$, the operators collected batteries and attempted to operate the DC-driven motor valves MOV-3A and MOV-2A. It is highly possible that the valves of the $\mathrm{IC}$ were working at the time.

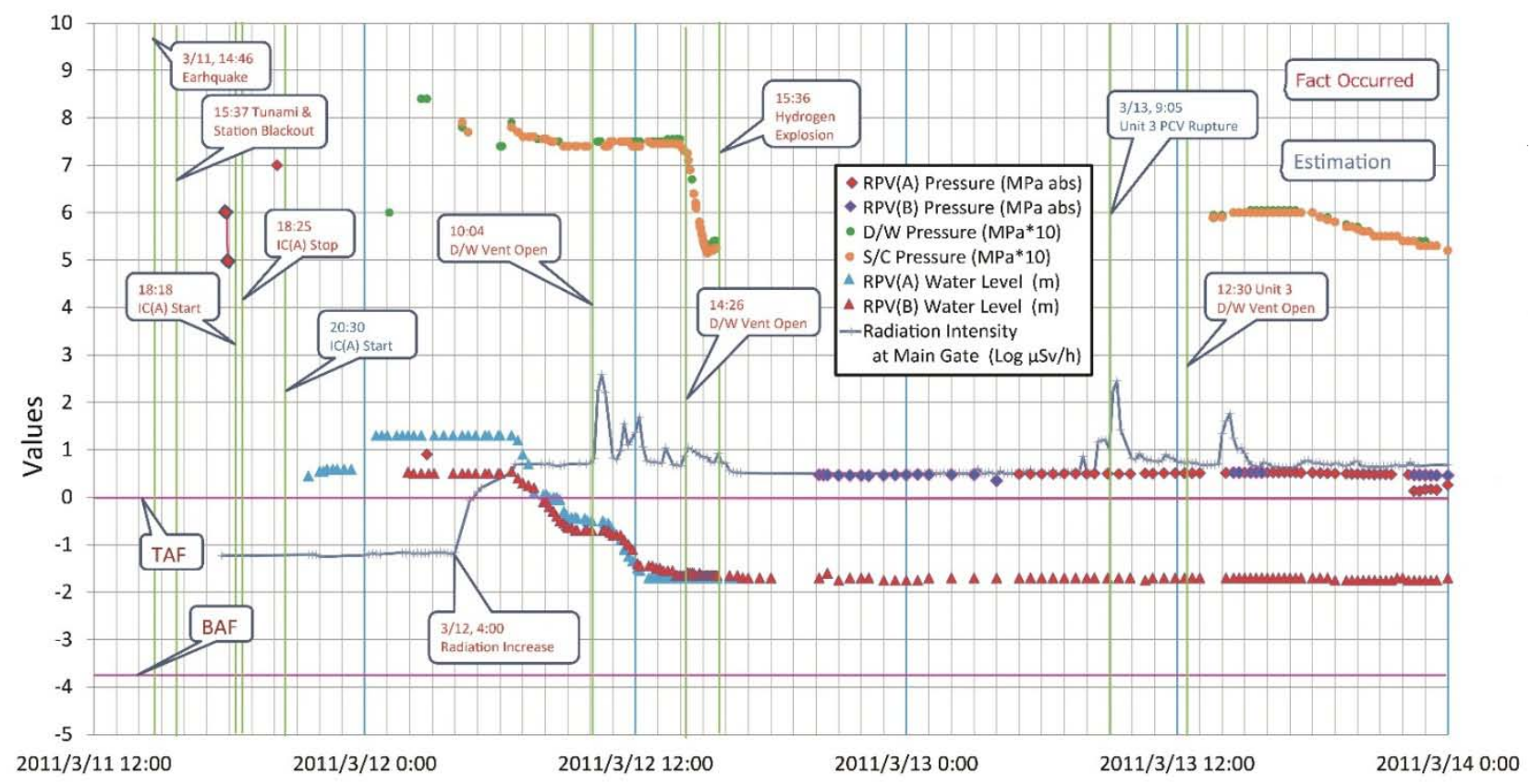

Fig. 8: Measured plant parameters of Unit 1, radiation intensity, and actual occurrences in the accident of the Fukushima Daiichi NPP

TEPCO released the plant parameters of the units of Fukushima Daiichi NPP and measurement data on the radiation intensity at various measurement points in the accident. Figure 8 shows the pressure of the RPV and $\mathrm{PCV}$, or the $\mathrm{D} / \mathrm{W}$ and $\mathrm{S} / \mathrm{C}$, and measured water levels above the TAF. The radiation intensities at the main gate are depicted on a logarithmic scale. The actual occurrences in the accident are indicated in 
Fig.8. We consider the time when the IC was restarted to be $20: 30$ on March 11 rather than 21:30, as reported in the initial report by TEPCO [26], because there is a record that the IC was working at 20:30 in Fig. 6. We think the rupture in the PCV of Unit 3 occurred at 09:05 on March 13, 2011 [17], which differs from the estimation presented by TEPCO [6].

There were two reactor water level meters in the RPV, and their data show different values. The water level was almost constant above the TAF from 21:30 on March 11 to 06:30 on March 12. As shown in the previous section $b$, the reactor water level meter shows the correct value when the water level is above the TAF. The data may not be accurate, but the discrepancies must be explained reasonably. TEPCO explained in the report on June 20, 2012, that "Therefore, water levels measured after core damage are assumed to be unreliable, while water levels taken via analysis are assumed to be closer to those in reality" [6].

The radiation measurement instruments located at various points in the NPP were working independently without the effect of the station blackout; hence, the data and measured times are correct. The data on radiation intensity have to be rationally explained based on the actual occurrences inside Unit 1 in reality.

We attempted to construct an accident scenario that explains all the data in Fig. 8, and to determine the actual occurrences in Unit 1 during the accident.

\section{d) Behavior of Valves and the Water Reservoir of IC}

When the earthquake occurred, the reactors stopped owing to reactor scram, and the ICs started automatically. Then, the operators stopped IC-B, and IC-A was intermittingly operated to maintain the temperature decrease within $55^{\circ} \mathrm{C} / \mathrm{h}$ or $100{ }^{\circ} \mathrm{F} / \mathrm{h}$. MOV-3 of system $A$ was closed when the tsunami arrived.

TEPCO [6] and the Investigation Committee on the Accident at the Fukushima Nuclear Power Stations [4] reported that the "fail-safe system" closed all valves connected to the ICs, and that they did not work after the tsunami. Conversely, TEPCO [13] reported that the AC power shut down occurred at 15:36:59, immediately after the tsunami attack. The DC power is estimated to have been active until at least 15:50[25]. The "fail-safe system" activates when the DC power goes off. These facts imply that the AC MOVs, i.e., MOV-1 and MOV-4, may have been fully open owing to the AC power blackout at the early stage of the accident. This fact was indicated by the author [HTC Rep.26.2, 2013/03/03], [9]. The NRA[19]indicated that MOV-1 and MOV-4 may have been open when the tsunami attacked. The operators attempted to operate IC-A by connecting DC batteries for automobiles. If the DC MOVs were open, it is highly possible that IC-A was operational after the tsunami struck.

TEPCO reported that the amount of water remaining in the reservoir tank of IC-A agreed with the estimated water volume of IC-A if it was not functional after the tsunami. The NISA disclosed the accident data published by TEPCO, where the faxes and original data of plant parameters of reactors were listed [26]. The plant parameter report at 00:30 on March 12 described that the water was injecting into the reservoir tank of the IC-A. As shown in Fig.6, the water was injecting to IC by a D/D FP. According to this evidence, IC-A may have been working at that time. The IC may have stopped before 04:45 on March 12 because there was evidence that the water injection to reservoir tank IC-A is suspending at $4: 45$, in the original plant parameters report, as shown in Fig. 7. From the previously mentioned data and evidence, it is highly likely that IC-A was functional after the tsunami attack and stopped before 4:45 on March 12.

The water injection to the reservoir tank, and the report of several eyewitnesses (TEPCO operators and workers), who saw steam ejection from the IC, were ignored in the Investigation Committee report on the "Accident at the Fukushima Nuclear Power Stations"[4]. TEPCO also ignored evidence that steam ejection was observed by the workers [25] at 21:30 on March 11. It was also reported in the original plant parameter data that the IC was functional [26]. These facts were ignored in the report of the Investigation Committee [4].

TEPCO claims that the increase in radiation dose in the R/B at 21:51 is an evidence of the early meltdown of the RPV because the IC was not working after the tsunami. However, the present analysis shows that the increase in radiation can be explained by an accident scenario, assuming that the IC was working after the tsunami. Furthermore, the behavior of the water level meters can also be reproduced by an accident scenario where the IC was working [HTC Rep.32.2, 2014/03/05].

\section{Proposed Accident Scenario}

In the present accident scenario, we assumed that the IC was, to a certain extent, functional after the station blackout, and the estimated breakdown of the RPV occurred considerably later than the estimation presented by TEPCO. Moreover, we constructed a detailed thermodynamic model to describe the equilibrium state of the RPV and PCV in the NPP. We determined that the measured data and original records are well described by the simulation using the thermodynamic model. Our simulation program is relatively small and operated on Microsoft Excel. It can be used to calculate one set of accident scenarios within a few seconds, and related diagrams are promptly displayed.

In the previous analysis of Unit 1 [HTC Rep.26.1 2013/02/10], [9], we constructed an accident scenario where IC-A was functional after the tsunami attack, and a small leak through a rupture with the equivalent 
diameter of $d_{R P V}=0.86 \mathrm{~cm}$ occurred immediately after the earthquake.

The NRA analyzed the pressure data from the PCV before the tsunami attack and concluded that the RPV leak did not occur because of the earthquake [11]. We compared the measured data of PCV pressure and the pressure estimation according to the previous accident scenario [9], which assumed an early leakage in the RPV. The previous pressure estimation overestimated the measured data; however, the previous scenario was able describe the rest of the measured pressure data except for the PCV pressure before the tsunami attack.

Based on this finding, we proposed a new accident scenario in which a small leakage occurred at a safety valve (SV) of the RPV at 20:26 on March 11, and a large leakage occurred at 06:20 on March 12 at another SV [HTC Rep.35.1, 2015/03/03]. The other scenario is similar to the previous one [9].

In the accident scenario of the present study, it is assumed that the RPV ruptured at 20:26 on March 11, just before IC-A was restarted at 20:30. According to the previous report [9], the water level was below the TAF, and it is expected that high-temperature vapor accumulated at the top of the RPV because the IC stopped at that time. It is also estimated that the abrupt increase in vapor pressure in the RPV may have caused a vapor ejection through an SV whose operating pressure was higher than the SRVs. The SV ejects the steam directory into the PCV or D/W, whereas SRVs eject the steam to the water in the S/C. This discharge of high-temperature vapor from the SV may cause a failure of the SV and create a continuous leak. We assumed that the leak occurred through a rupture with an approximate diameter $d_{R P V}=1.7 \mathrm{~cm}$ to adjust for the measured PCV pressure data.

The remaining aspects of the accident scenario are similar to the previous one [9]. The present accident scenario is as follows:

1. IC-A was operated manually from $18: 18$ to $18: 25$ on March 11.

2. A small RPV leak occurred at 20:26. It is suspected that the position of the leak may have been at a SV.

3. IC-A started again at 20:30 according to the original records [26] and Fig. 6. It is estimated to have stopped at approximately 03:00on March 12.

4. The PCV leak occurred at 03:30 in the lower part of the PCV. This caused an increase in the radiation dose at 04:00 at the main gate of the NPP.

5. A large leak from the RPV occurred at 06:20, probably from an SV, and it caused a further increase in the PCV rupture at 06:23.

6. The RPV ruptured again at 16:00 at the bottom of the RPV owing to drying out of the RPV.

The details of the accident scenario are listed in Table 2. It should be noted that the estimated areas where rupture occurred in the PCV between 06:23 and 09:00 on March 12 were adjusted to satisfy the measured pressure data. The assumption of phase equilibrium was not satisfied at that time, because the water level was lower than the TAF and the water vapor was not saturated steam.

The water injection rates to the RPV are smaller than those reported by TEPCO. A recent report by TEPCO mentioned that all injected water may not have reached the RPV because there was a bypass in the injection line. It is also noted that the initial water injection at approximately 04:00 on March 12, 2011, may not have reached the RPV because the pressure was too high. According to the analysis of the water level meter [HTC Rep.32.2, 2014/03/05], the water injection quantities listed in Table 1 are smaller than the values reported by TEPCO.

Table 2: List of events that occurred in the accident scenario of Unit 1 . The facts with $\left({ }^{*}\right)$ indicate the estimation in the present scenario

\begin{tabular}{|c|c|c|c|}
\hline Time & Time after Scram & Facts & $\begin{array}{c}\text { Scenario } \\
\text { Parameters }\end{array}$ \\
\hline $\begin{array}{c}\text { March 11 } \\
14: 46\end{array}$ & 0 & Earthquake, Succeeded in Scram & \\
\hline $14: 52$ & $0: 06$ & IC-A,IC-B Auto Start & \\
\hline $14: 52$ & $0: 06$ & Simulation Start * & \\
\hline $15: 02$ & $0: 16$ & IC-A,B Manual Stop & \\
\hline $15: 16$ & $0: 30$ & IC-A Manual Start & \\
\hline $15: 18$ & $0: 32$ & IC-A Manual Stop & \\
\hline $15: 22$ & $0: 36$ & IC-A Manual Start & \\
\hline $15: 25$ & $0: 39$ & IC-A Manual Stop & \\
\hline $15: 31$ & $0: 45$ & IC-A Manual Start & \\
\hline $15: 34$ & $0: 48$ & IC-A Manual Stop & \\
\hline $15: 36: 59$ & $0: 59: 59$ & Tsunami Attack, AC Blackout & \\
\hline $15: 50$ & $1: 04$ & DC Blackout & \\
\hline $15: 59$ & $1: 13$ & SRV Blow* & \\
\hline
\end{tabular}




\begin{tabular}{|c|c|c|c|}
\hline 18:18 & $3: 24$ & $\begin{array}{l}\text { IC-A Manual Start, } \\
\text { Vapor Emission from IC was Observed }\end{array}$ & \\
\hline 18:25 & 3:39 & IC-A Manual Stop & \\
\hline 19:12 & $4: 26$ & SRV Blow* & \\
\hline 19:30 & $4: 44$ & Water Level at TAF* & \\
\hline 20:07 & $5: 21$ & RPV Pressure 6.7 -7.3 MPa & \\
\hline 20:26 & $5: 40$ & Small Leakage in RPV from SV* & $d_{R P V}=1.7 \mathrm{~cm}$ \\
\hline $20: 30$ & $5: 44$ & IC-A Start & \\
\hline $21: 30$ & $6: 44$ & $\begin{array}{l}\text { RPV Pressure-decreasing Vapor Emission } \\
\text { from IC was Observed }\end{array}$ & \\
\hline $21: 51$ & 7:05 & Off-limit R/B due to Radiation Dose Increase & \\
\hline $\begin{array}{c}\text { March } 12 \\
0: 30\end{array}$ & $9: 44$ & Injection of Water to IC-A Reservoir & \\
\hline $2: 45$ & $11: 59$ & RPV Pressure 0.901MPa & \\
\hline 3:00 & $12: 14$ & IC-A Stop* & \\
\hline $3: 30$ & $12: 44$ & PCV Rupture* & $d_{P C V}=3.5 \mathrm{~cm}$ \\
\hline 4:00 & $13: 14$ & PCV Rupture Change* & $d_{P C V}=3.7 \mathrm{~cm}$ \\
\hline $4: 15$ & $13: 29$ & Injection of Water to IC-A Reservoir Stop & \\
\hline $6: 00$ & $15: 14$ & PCV Rupture Change* & $d_{P C V}=3.3 \mathrm{~cm}$ \\
\hline $6: 20$ & $15: 34$ & RPV Rupture* & $d_{R P V}=7 \mathrm{~cm}$ \\
\hline $6: 23$ & $15: 37$ & PCV Rupture Increase* & $d_{P C V}=15 \mathrm{~cm}$ \\
\hline $6: 26$ & $15: 40$ & PCV Rupture Change* & $d_{P C V}=14.7 \mathrm{~cm}$ \\
\hline $6: 40$ & $15: 54$ & PCV Rupture Change* & $d_{P C V}=12 \mathrm{~cm}$ \\
\hline $6: 52$ & 16:06 & Water Level BAF* & \\
\hline $7: 10$ & $16: 24$ & PCV Rupture Change* & $d_{P C V}=9.8 \mathrm{~cm}$ \\
\hline $8: 00$ & $17: 41$ & Water Injection to PRV Start* & $\dot{m}_{i n j}=0.5 \mathrm{~kg} / \mathrm{s}$ \\
\hline 8:05 & $17: 19$ & PCV Rupture Change* & $d_{P C V}=7.7 \mathrm{~cm}$ \\
\hline 9:00 & $18: 14$ & PCV Rupture Change* & $d_{P C V}=7.9 \mathrm{~cm}$ \\
\hline $10: 16$ & $19: 30$ & D/W Vent Open & $d_{P C V}=9 \mathrm{~cm}$ \\
\hline $10: 25$ & $19: 39$ & D/W Vent Close & $d_{P C V}=7.7 \mathrm{~cm}$ \\
\hline $14: 26$ & $23: 40$ & D/W Vent Open & $d_{P C V}=10.4 \mathrm{~cm}$ \\
\hline $14: 50$ & $24: 04$ & Water Injection to RPV Stop & $\dot{m}_{i n j}=0$ \\
\hline $15: 20$ & $24: 34$ & D/W Vent Close* & $d_{P C V}=8 \mathrm{~cm}$ \\
\hline $15: 36$ & $24: 50$ & R/B Hydrogen Explosion & \\
\hline $16: 00$ & $25: 14$ & RPV Rupture Area Increase* & $d_{R P V}=10 \mathrm{~cm}$ \\
\hline $19: 04$ & $28: 18$ & Sea Water Injection to RPV Start & $\dot{m}_{i n j}=2 \mathrm{~kg} / \mathrm{s}$ \\
\hline $21: 45$ & $30: 59$ & Sea Water Injection to RPV Stop & $\dot{m}_{i n j}=0$ \\
\hline $23: 50$ & 33:04 & Sea Water Injection to RPV Start & $\dot{m}_{i n j}=2 \mathrm{~kg} / \mathrm{s}$ \\
\hline $\begin{array}{l}\text { March } 13 \\
18: 00 \\
\end{array}$ & $51: 14$ & Sea Water Injection to RPV Change & $\dot{m}_{i n j}=2.5 \mathrm{~kg} / \mathrm{s}$ \\
\hline $\begin{array}{c}\text { March } 14 \\
1: 10 \\
\end{array}$ & $58: 24$ & Sea Water Injection to RPV Stop & $\dot{m}_{i n j}=0$ \\
\hline $20: 00$ & $77: 14$ & Sea Water Injection to RPV Start & $\dot{m}_{i n j}=2 \mathrm{~kg} / \mathrm{s}$ \\
\hline
\end{tabular}


Table 2 lists the actual accident events and the accident scenarios estimated from the limited data and testimonies. At the beginning of the Fukushima Daiichi NPP accident, only limited data were available, and that data were often not very precise. The estimated accident scenario at the early stage of the analysis was significantly different from the truth. The scenario presented by the author in the first stage [HTC Rep. $14.2,2011 / 5 / 11]$ has undergone multiple changes since March11, 2011.

Incorrect data can be corrected for good reasons to derive a more truthful accident scenario. Furthermore, by considering the new data, such as the progress of the internal investigation in the reactor, it is possible to estimate the accident even closer to the truth. It is possible to derive accident scenarios that are closer to the truth by correcting erroneous data for appropriate reasons.

Nevertheless, there are still several in consistencies and unclear points in the present accident scenario listed in Table 2. For example, the restart time of the IC is assumed to be 20:30, which is one hour earlier than the generally accepted restart time. In addition, the PCV destruction times are complicated in the scenario listed in Table 2; however, the scenario in the previous report is simpler and more consistent with the radiation intensity data. This is because the analytical model used in this study assumes vapor-liquid equilibrium in the RPV and PCV; therefore, transient phenomena cannot be described.

Estimation of the rupture location and time on the RPV and PCV, which will be described in subsequent sections, are not in the realm of speculation. However, it is also true that the accident scenario described in Table 2 can explain many of the measured data and events that occurred so far, as will be explained subsequently.

\section{Analysis Model}

Figure 9 shows the construction diagram of Unit 1 and its physical model for thermo-fluid analysis of the accident scenario. Figure 9 describes the status of Unit 1 as of 12:00 on March 13, 2011, when the RPV and PCV ruptured; moreover, the explosion due to the accumulation of hydrogen at the top portion of the $\mathrm{R} / \mathrm{B}$ occurred at 15:36 on March 12.

\section{a) Analysis Model of RPV and PCV}

The physical model in Fig. 9 is simplified to a thermodynamic model, as shown in Fig. 10. The RPV and PCV are simplified vessels that contain vapor and liquid water at saturation conditions. The thermodynamic model of the saturation conditions is similar to the previous models [8], [9]. This model is based on the conservation of mass and energy in the vessels, and the assumption of the phase equilibrium of water and vapor in the vessels. Details of the model were described in the previous report [8]. 


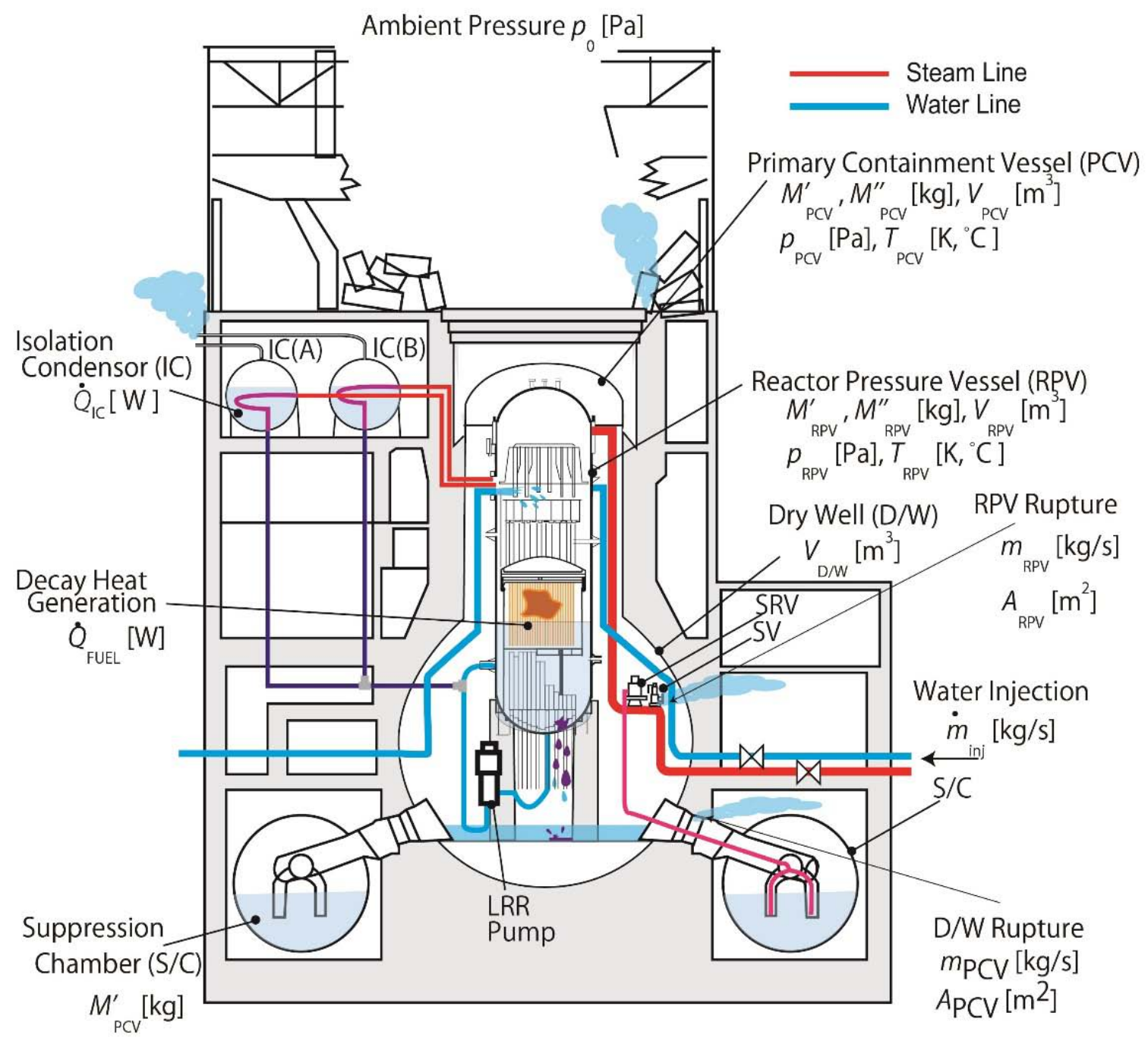

Fig. 9: Physical model of Unit 1 as of March 13, 2011 at 12:00 [9]

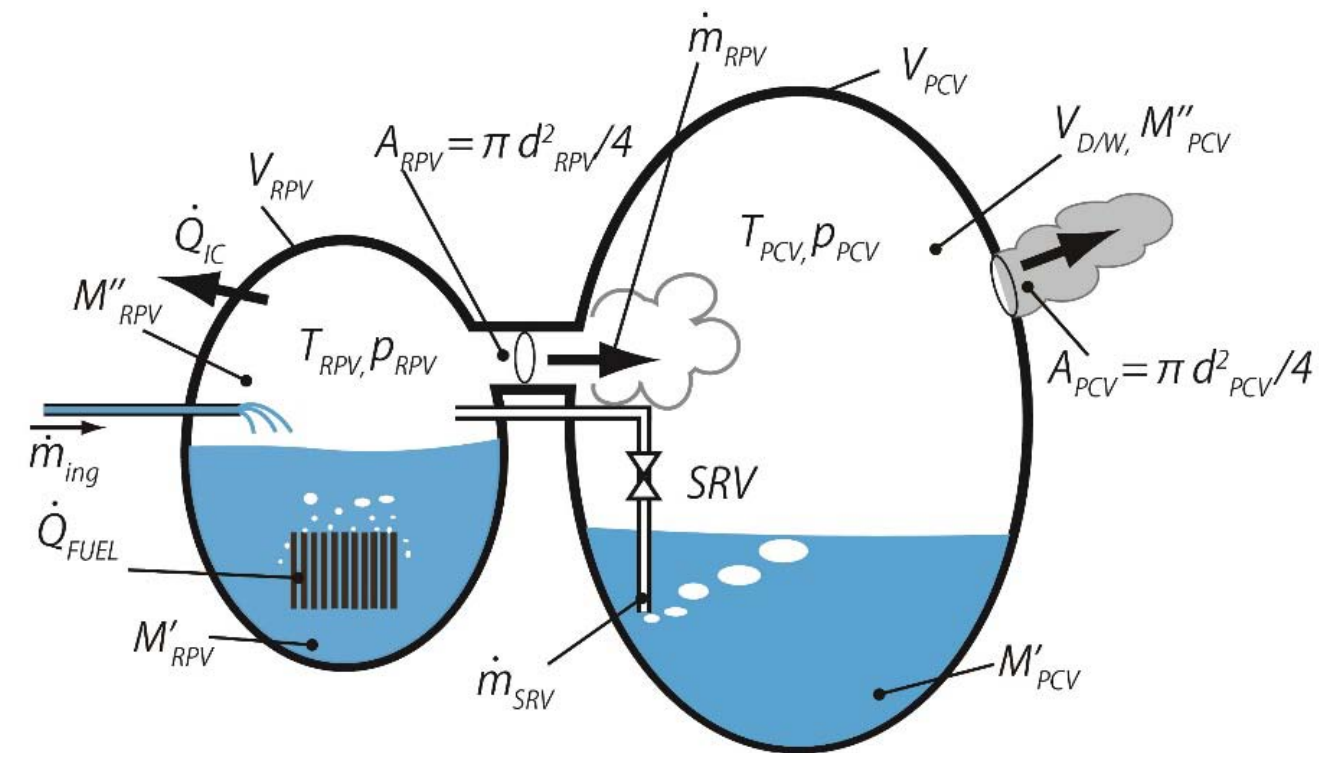

Fig. 10: Phase-equilibrium thermodynamic model of RPV and PCV 
Water injection to the RPV, vapor leakage from the RPV to PCV, vapor ejection to the S/C, decay heat, and cooling rate of the ICs are denoted as $\dot{m}_{i n j}, \dot{m}_{R P V}, \dot{m}_{S R V}[\mathrm{~kg} / \mathrm{s}] \dot{Q}_{F U E L}, \dot{Q}_{I C}[\mathrm{~W}]$ respectively.

$$
\begin{aligned}
& \mathrm{d} T_{R P V}= \frac{\left[-\left(\dot{m}_{R P V}+\dot{m}_{S R V}\right)\left(h_{R P V}^{\prime \prime}-h_{R P V}^{\prime}\right)+\dot{m}_{i n j}\left(h_{i n j}^{\prime}-h_{R P V}^{\prime}\right)+\dot{Q}_{F U E L}-\dot{Q}_{I C}\right] \mathrm{d} t}{\left[M_{R P V}^{\prime}\left(c_{p, R P V}^{\prime}+\frac{\left(h_{R P V}^{\prime}-h_{R P V}^{\prime}\right)^{2}}{p_{R P V} T_{R P V} v_{R P V}^{\prime}}\right)+c_{p, R P V}^{\prime}\left[M_{R P V}^{\prime}+\left(-\dot{m}_{R P V}-\dot{m}_{S R V}+\dot{m}_{i n j}\right) \mathrm{d} t\right]-\frac{V_{R P V}\left(h_{R P V}^{\prime \prime}-h_{R P V}^{\prime}\right)}{T_{R P V} v_{R P V}^{\prime}}\right]} \\
& \mathrm{d} T_{P C V}=\frac{\left[\left(\dot{m}_{R P V}+\dot{m}_{S R V}\right)\left(h_{R P V}^{\prime \prime}-h_{P C V}^{\prime}\right)-\dot{m}_{P C V}\left(h_{P C V}^{\prime \prime}-h_{P C V}^{\prime}\right)\right] \mathrm{d} t}{\left[M{ }_{P C V}\left(c_{p, P C V}^{\prime}+\frac{\left(h_{P C V}^{\prime}-h_{P C V}^{\prime}\right)^{2}}{p_{P C V} T_{P C V} v_{P C V}^{\prime}}\right)+c_{p, P C V}^{\prime}\left[M_{P C V}^{\prime}+\left(\dot{m}_{R P V}+\dot{m}_{S R V}-\dot{m}_{P C V}\right) \mathrm{d} t\right]-\frac{V_{P C V}\left(h_{P C V}^{\prime}-h_{P C V}^{\prime}\right)}{T_{P C V} v_{P C V}^{\prime}}\right]}
\end{aligned}
$$

Here, $h, v$, and $c_{p}$ represent the enthalpy, specific volume, and specific heat at constant pressure, respectively. The notations "." and "." express the states of water and vapor at the equilibrium condition, respectively. The model assumes that the temperature in the RPV and PCV is uniform. Hence, this model cannot describe the phenomena when the water level is below the TAF and the vessel is filled with superheated vapor.

As shown in the previous report [7], the time history of the decay heat in Unit 1 can be estimated relatively accurately. Because the decay heat is released from the ruptured vessel as steam, the mass flow rate of the steam can be estimated. Assuming the rupture cross section, the pressure difference between the inside and outside of the vessel can be estimated using Bernoulli's equation. Thus, the relationship between the

$$
\dot{m}=C A \rho^{*} a^{*}=C A \rho_{0}\left(\frac{2}{\kappa+1}\right)^{\left(\frac{1}{\kappa-1}\right)} a_{0}\left(\frac{2}{\kappa+1}\right)^{\left(\frac{1}{2}\right)}=C\left(\frac{2}{\kappa+1}\right)^{\left(\frac{1}{\kappa-1}+\frac{1}{2}\right)} A \rho_{0} a_{0} \text {, for } \frac{p_{1}}{p_{o}}<\left(\frac{2}{\kappa+1}\right)^{\left(\frac{\kappa}{\kappa-1}\right)} \text {, }
$$

where $a[\mathrm{~m} / \mathrm{s}]$ is the speed of sound, $\kappa$ is the specific heat ratio of the vapor, and a value of 1.34 for saturated vapor at $100^{\circ} \mathrm{C}$ was used as an approximation. The subscript 0 indicates the value in the vessel, and * indicates the state at the velocity of sound. The flow coefficient of the orifice was assumed to be the same as that of a subsonic orifice at the speed of sound. These equations can be used to estimate the steam flow from the RPV to the PCV or from the PCV to the external environment. steam flow rate, fracture aperture area, and pressure difference inside and outside the vessel is expressed by the following equation [27]:

$$
\dot{m}=C A \sqrt{2 \rho_{1}\left(p_{0}-p_{1}\right)},
$$

where $p_{0}[\mathrm{~Pa}]$ is the pressure inside the vessel, $p_{1}[\mathrm{~Pa}]$ is the pressure outside the vessel, and $\rho_{1}\left[\mathrm{~kg} / \mathrm{m}^{3}\right]$ is the density at the minimum cross-sectional area of the mass flow. The flow coefficient of the orifice $C$ was set to 0.60 for the inlet orifice.

When the pressure difference becomes large, the flow rate through the vessel opening reaches the speed of sound. The flow rate at that time is expressed by the following equation [24]:

When the RPV ruptures and the vapor is ejected to the vapor-phase space of the PCV or D/W, the temperature varies between the D/W and the S/C. In this case, the vapor in the RPV is ejected to the PCV in the adiabatic condition. Using the adiabatic expansion model adopted in a previous report [7], [9], the pressure and temperature changes in differential time $\mathrm{d} t$ is expressed as follows.

$$
\begin{aligned}
\mathrm{d} V_{D / W}= & \left\{\left(\dot{m}_{R P V} v_{R P V}^{\prime}\right)\left(p_{R P V} / p_{D / W}\right)^{1 / \kappa}-\left(\dot{m}_{P C V} V_{P C V}\right)\right\} \mathrm{d} t \\
\mathrm{~d} h_{D / W}^{\prime}= & \frac{M_{D / W} h^{\prime \prime}{ }_{D / W}+\left(\dot{m}_{R P V} h_{R P V}-\dot{m}_{P C V} h_{D / W}\right) \mathrm{d} t}{M_{D / W}+\left(\dot{m}_{R P V}-\dot{m}_{P C V}\right) \mathrm{d} t}-h_{D / W}^{\prime \prime} \\
& \frac{T_{D / W}+\mathrm{d} T_{D / W}}{T_{D / W}+\mathrm{d} h^{{ }_{D / W}} / c_{p}}=\left[\frac{V_{D / W}+\mathrm{d} V_{D / W}}{V_{D / W}}\right]^{K-1}
\end{aligned}
$$




$$
\frac{p_{D / W}+\mathrm{d} p_{D / W}}{p_{D / W}}=\left[\frac{V_{D / W}+\mathrm{d} V_{D / W}}{V_{D / W}}\right]^{\kappa}
$$

Where, the notations follow the ones in Fig. 10. Note that the analysis according to the adiabatic expansion model does not give anaccurate estimation when the water level is below the TAF, and the RPV is filled with superheated vapor. This is because the present model assumes that the ejected vapor is at the saturation condition.

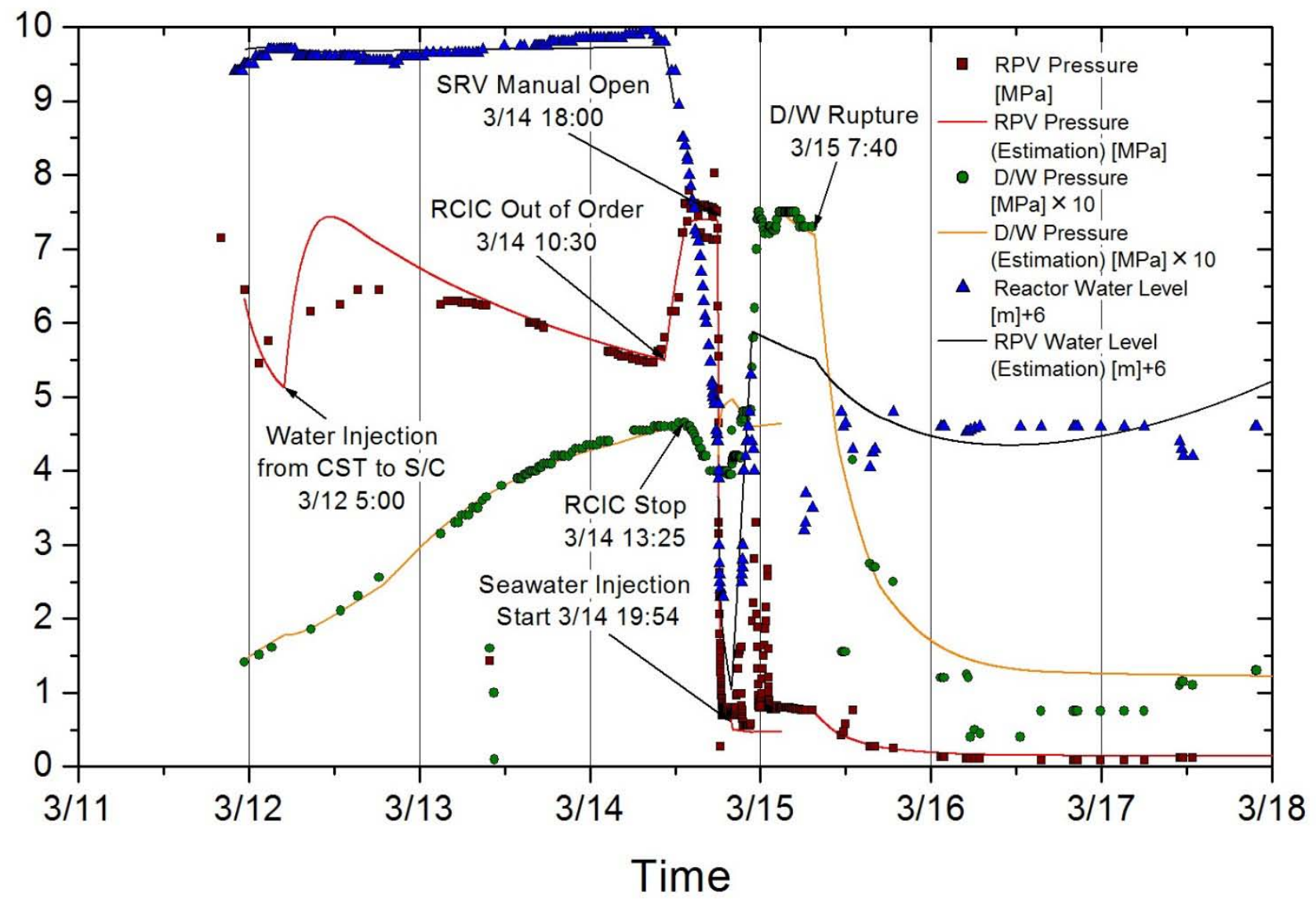

Fig. 11: Comparison with measured plant parameters of Unit 2 and analysis using the thermodynamic model [8]

To demonstrate the accuracy of the present thermodynamic model when compared to measured data of the accident, a comparison of the present analysis with the measured data of Unit 2 is shown in Fig. 11. Our accident scenario of Unit 2 [8] is similar to that of TEPCO. And our analysis result shows better agreement than that of TEPCO.

TEPCO used a large computer simulation code called MAAP. It is a large simulation program to analyze the transient phenomena during a nuclear plant accident; however, it requires a long time to simulate an accident scenario. The present simulation can be conducted using Microsoft Excel, and it requires only a few seconds to simulate one accident scenario. The program can also express appropriate diagrams, as shown in Fig. 11, to examine the analysis results. Accordingly, our simulation program can provide a large number of accident scenarios to obtain good agreement with the data measured during the accident. b) Analysis of Reactor Water Level Meter

TEPCO constructed a scenario of IC shutdown and early meltdown of the reactor core, claiming that the indicated value of the water level meter in Unit 1 is completely unreliable [6]. The Government Accident Independent Investigation Commission [4] also qualitatively stated the reasons why the water level gauges were not working properly based on the report by TEPCO [6]. However, they did not quantitatively evaluate the readings of the water level meters at that time, and stated that the indicated values of the water level meters were completely wrong. The later report submitted by TEPCO [16] suggests that the indicated values of the water level meters at that time may have contained some information.

We used the model illustrated in Fig. 5, and try to reproduce the water level meter measurements, as shown in Fig. 8. As described in Section III a, the water level meter gives the correct value when the water level 
in the RPV is higher than the TAF because of the structure of the reference condensing water chamber. The reference water level $Z_{\text {Ref }}$ is $L_{1}$, as shown in Fig. 5, when $Z_{F}$ is above the TAF. When the water level $Z_{F}$ is lower than the TAF, the relationship between the apparent water level $Z_{\text {Level }}$ and the actual water level $Z_{F}$ is expressed by the following equation.

$$
Z_{\text {Level }}=Z_{F}-Z_{\text {Ref }}+L_{1}
$$

When boiling occurs in the fuel assembly, the water head of the fuel assembly $H_{\mathrm{F}}$ and the apparent water level $H_{w}$ may be different. Thus, when water boils in the vertical channel, the apparent water level $H_{\mathrm{w}}$ increases owing to the bubbles. Even if the water level $H_{F}$ falls below the TAF level, the reference water level $Z_{\text {Ref }}$ is considered to maintain the reference level of $L_{1}=5.11$ $\mathrm{m}$ as long as the apparent water level $H_{\mathrm{w}}$ in the fuel assembly channel reaches the TAF, as shown in Fig. 5.

When the water level in the channel drops below the TAF, the reference water level $Z_{\text {Ref }}$ in the reference pipe starts to decrease. The speed of the water level reduction depends on the temperature distribution in the RPV and the pipeline layout. In this study, it is assumed that the reference surface water level $Z_{\text {Ref }}$ decreases at the same rate as the RPV water level $Z_{F}$ decreases. It is also assumed that once the reference surface water level decreases, it will not return to the original level owing to the vertical temperature distribution in the RPV. In addition, it is assumed that the lowered reference water level will be maintained while the $\mathrm{IC}$ is in operation.

It was assumed that for the water level meter of system $B$, the water level at the reference surface was suspended at $3.0 \mathrm{~m}$ above the TAF when the IC was restarted at 20:30, and the water level remained unchanged until the IC was stopped at 3:00. At the water level meter in system $A$, the reference surface water level dropped again at 23:30 and reached $2.5 \mathrm{~m}$ above the TAF, and then the water level remained constant until the IC stopped.

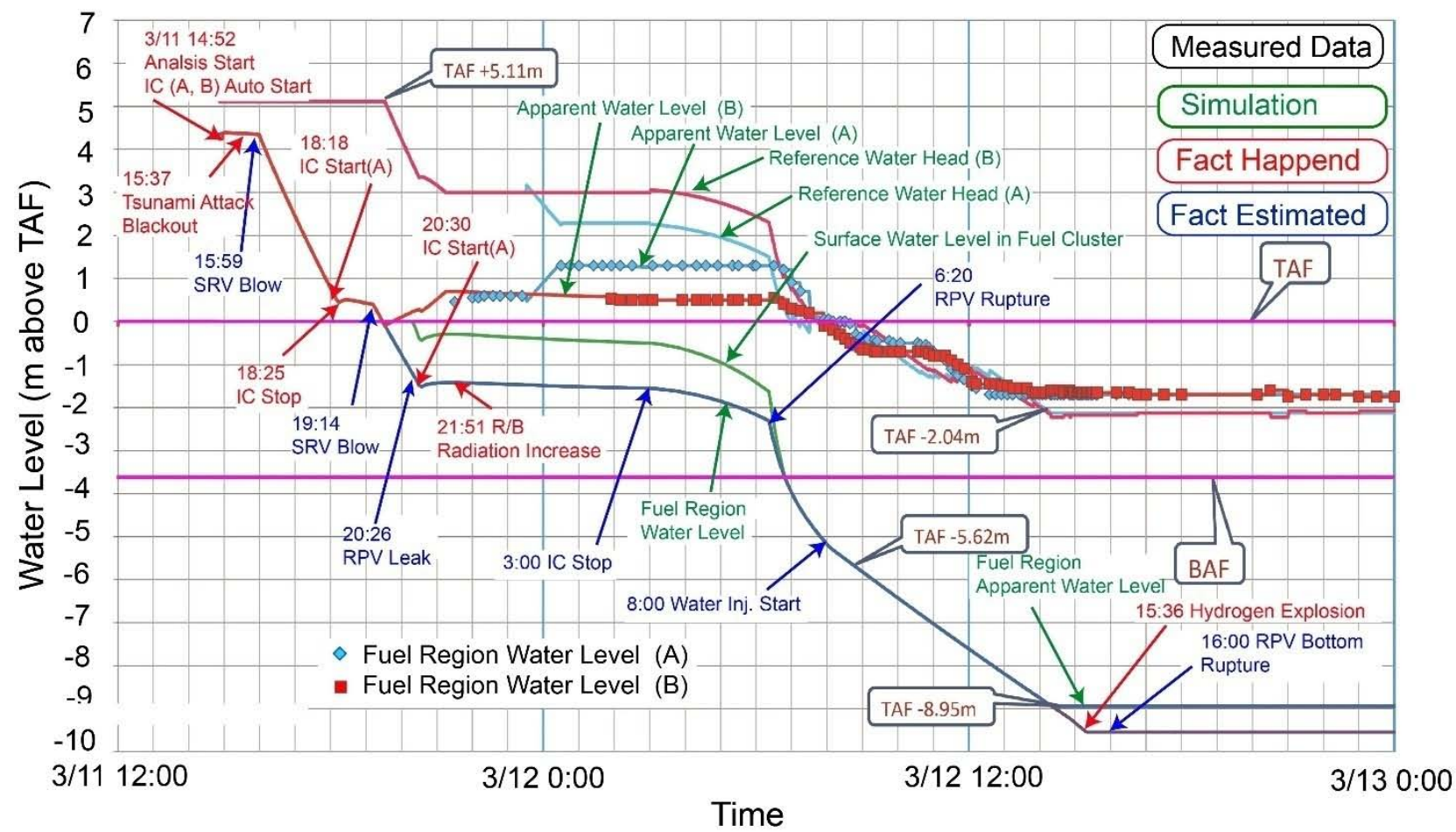

Fig. 12: Reproduction of water level data in RPV using the estimated water level with the accident scenario in the present report

To validate the above-mentioned analysis model and the assumptions, a comparison of the measured water level and our analysis is shown in Fig.12. The calculated reactor water level was obtained from the thermodynamic model using the accident scenario listed in Table 2.

With the above-mentioned assumptions, the water level meter indication at the accident can be reproduced. However, the validity of the speed at which the water level lowered in the reference level meter when the water level fell below the TAF is not clear; however, the above-mentioned assumptions can explain the data obtained from the water level meters at that time. TEPCO reported that there is horizontal piping of the reference level meter, and that system $B$ is approximately $3 \mathrm{~m}$ longer than system $\mathrm{A}$. At this stage, 
the details of the water level piping have not been disclosed. If there is a type of horizontal piping, such as a piping around TAF $+3.0 \mathrm{~m}$ and $\mathrm{TAF}+2.5 \mathrm{~m}$, this hypothesis can be proven. At present, as the location of the piping is unknown, this assessment is only a speculation.

After the IC was shut down at 03:00 on March 12 the reference water level was assumed to decrease at the same rate as the water level in the RPV. When the RPV ruptured at 06:20 and the pressure decreased rapidly, the reactor water level decreased rapidly. The present estimation with these assumptions describes the measured water level after the RPV rupture.

As shown in Fig. 5, when the reference water level is below TAF $-2.04 \mathrm{~m}$, the water level in the pipe $Z_{\text {Ref }}$ does not decrease anymore because the pipe goes outside the PCV. Further, the apparent water level in the fuel region $Z_{F}$ does not decrease because the pipes of the water level in the RPV also go out of the PCV at TAF -8.94 $\mathrm{m}$. Therefore, the apparent water level $Z_{\text {Level }}$ becomes constant after 14:20. This estimation is in good agreement with the measured apparent water level.
TEPCO attempted to reproduce the measurement of reactor water level meters and claimed that they succeeded in reproducing the data with the accident scenario simulated by TEPCO [16] in the attachments 1-6. The scenario simulated by TEPCO assumed that the water level became the BAF at 19:40 on March 11, which is significantly earlier than our estimation. When we examined the data in the attachment 1-6 [16], the "calculated variable leg water level above PCV penetration" in the attachment could not be understood. TEPCO did not explain the calculation procedure.

\section{Vi. Results and Discussion}

\section{a) Pressures in PCV}

Figure 13 shows the pressure simulations in the RPV and PCV according to the present accident scenario, which is listed in Table 2. The measured data of pressure in the D/W, S/C, and RPV, as shown in Fig. 8 , were compared with the present simulation. The radiation dose at the main gate of the NPP is also depicted in Fig. 13.

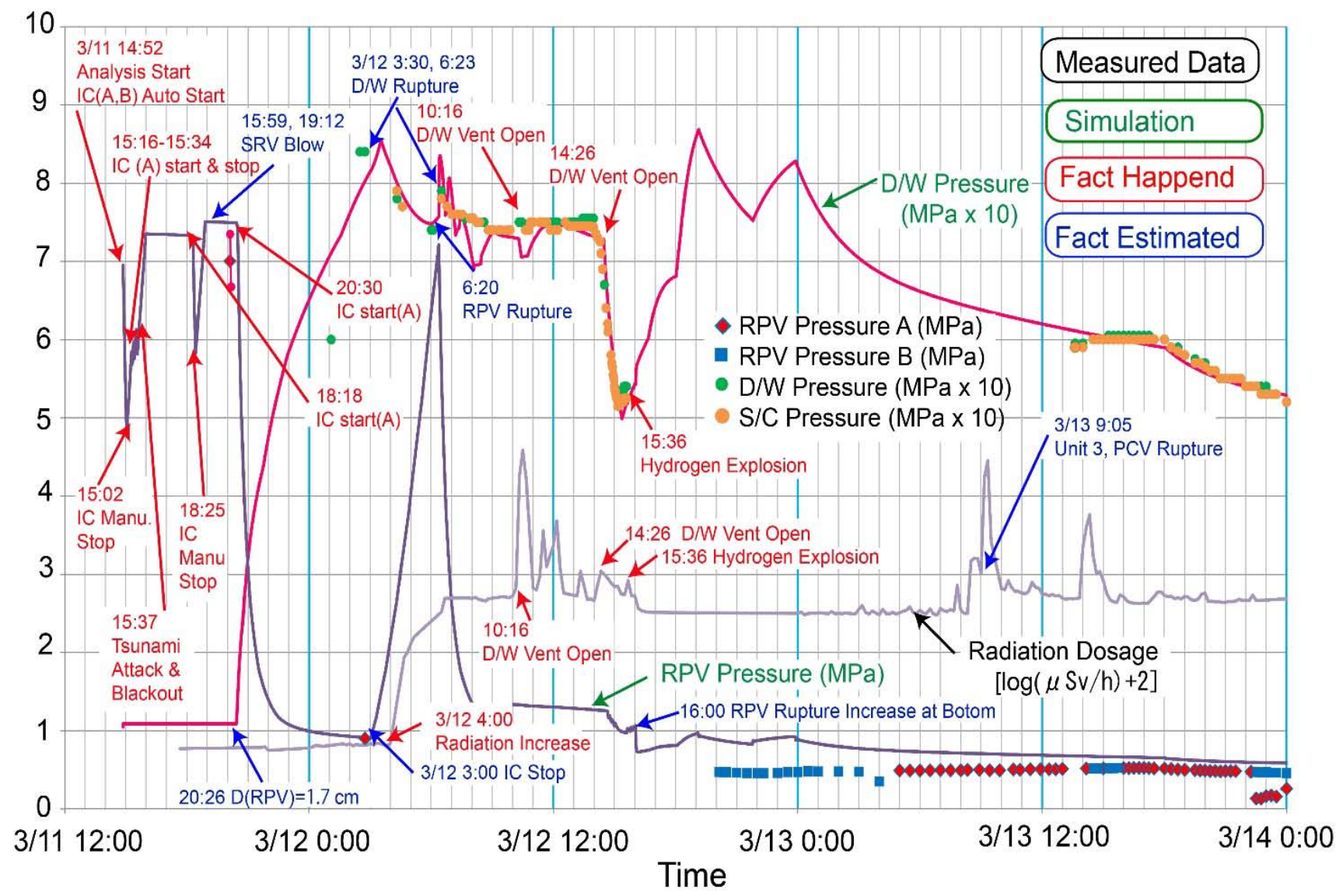

Fig. 13: Measured and estimated vessel pressures according to the present accident scenario. This simulation assumes that the IC was operating until 03:00 on March 12. We assume that a small leak from the RPV occurred at 20:26 on March 11, the PCV ruptured at 03:30 on March 12, and the ruptured area of the PCV increased at 06:23; the RPV ruptured in the vapor phase at 6:20. The RPV ruptured again at the bottom portion at approximately at 16:00. 
The pressure estimation of the PCV, i.e., the S/C and $\mathrm{D} / \mathrm{W}$, agrees well with the measured data, except for the measurement at 01:05 on March 12. This datum did not appear in the original data reported at that time [26]. The areas where rupture occurred in the PCV from 06:23 to $09: 00$ on March 12 were set to satisfy the measured data, because the assumption of phase equilibrium is not satisfied when the water level is lower than the TAF. Furthermore, superheated vapor was ejected from the RPV to D/W at that time.

We suspect that when the water level became lower than the TAF at 20:26 on March 11, the temperature of the steam increased and the zirconium sheath of the fuel rods reacted with the hightemperature steam, resulting in the generation of hightemperature hydrogen gas. This high-temperature steam and hydrogen gas may leak from the RPV; consequently, the pressure in the PCV starts to increase. In the present accident scenario, we assumed that the RPV had a small leak at 20:26.

This accident scenario explains that the reason for the increase in the radiation level in the R/B at 21:51, because the leaked contaminated gas from the RPV was stored in the PCV, resulting in an increase in the radiation in the R/B at that time. Then, the PCV ruptured at around 03:30 on March 12 owing to the high pressure. At this stage, the IC had stopped, and the water level was lower than that at 20:26 on March 11. The ruptured area was estimated to be of an equivalent diameter of $d_{R P V}=1.7 \mathrm{~cm}$. The ruptured area increased at 06:23 owing to the steam ejection from the RPV that ruptured at 06:20. The real rupture area of the PCV cannot be estimated because the superheated vapor cannot be estimated using Eqs. (4) and (5). When water was injected into the RPV, the ejected steam became saturated again. According to the estimation at 08:00, the rupture diameter was approximately $8 \mathrm{~cm}$, which is in good agreement with our early estimation [9].

The pressure after 10:26 decreased owing to the venting of the PCV. As listed in Table 2, the apparent rupture area increased owing to the vent motion of the PCV and the area returned to the previous value when the venting valve was closed. Note that the rupture area did not change with the hydrogen explosion at 15:36. This indicates that the rupture position was in the lower part of the PCV, as specified by the author [7]. This was also proved by TEPCO [13].

The radiation intensity increased 12 times between 04:00 and 04:40, and it also increased between 05:10 and 06:30. These increases in radiation dose agree with the present estimation of the PCV rupture times of $03: 30$ and $06: 23$. The radiation dose increased in the $R / B$ at 21:51on March 11; consequently, entering the building was prohibited. The radiation dose at the main gate did not increase at that time, as shown in Fig. 13. This implies that the contaminated gases that leaked from the RPV at 20:26 into the PCV may not have leaked into the environment. The water level of the RPV was under the TAF from the present estimation, and the contaminated vapor in the RPV may have leaked to the PCV after 20:26.

\section{b) Pressure Values in RPV}

The pressure estimation of the RPV by the present accident scenario is also shown in Fig. 13. This estimation assumes that IC-A was working between the times of $18: 18$ and 18:25. It also assumes that the IC was restarted at 20:30 according to the original data presented by TEPCO [26] and as shown in Fig. 6. This analysis assumes that the IC was nonfunctional at approximately 03:00 on March 11. It is suspected that the hydrogen produced by the zirconium-water-vapor reaction accumulated in the RPV, and the accumulated gas stopped the condensation of vapor in the IC.

This estimation of the time at which the IC stopped functioning is significantly later than that estimated by TEPCO [16]. The report published by TEPCO states that "When compared with the progression in the IC continuous operation after 18:25, the continued IC operation delayed the RPV damage and let to less erosion of the containment vessel concrete. But in the overall progression of the accident, it would be quite likely that there was only a minor difference from what actually occurred in Unit-1." TEPCO estimated that the IC became nonfunctional because the accumulated hydrogen deteriorated the condensation ability in the $\mathrm{IC}$ in the early stage of the accident.

The estimation presented by TEPCO may be possible when the condensation heat transfer in the IC is a natural convection type of heat transfer such as the condenser in Fig. 1. The condenser in the power plant condenses the vapor outside the heat transfer pipe and cooling water is circulated in the pipe. However, in the case of the IC, the condensing steam flows in the pipe, and the cooling water is boiling outside the pipe. As shown in Fig. 9, the ICs were placed at high positions. The condensed water in the IC is subjected to a large suction head owing to the large difference in height between the IC and the entrance of the condensed water at the RPV. In this case, we consider that the forced convection condensation may have continued after the generation of hydrogen gas. Hence, we estimated that the IC became nonfunctional at approximately 03:00 on March 12.

According to the discussion in a previous report [9], the cooling performance of the IC was significantly greater than the decay heat generated when the operators restarted IC-A at 18:18, which was $3.5 \mathrm{~h}$ after the scram. The pressure quickly decreased after the restart of the IC. The pressure increased after IC-A stopped manually at 18:25; then, the SRV blew steam to the $S / C$ and the water level in the RPV decreased. We 
assumed that the $\mathrm{IC}$ restarted at 20:30. At that time the water level was below the TAF, as shown in Fig. 12.

It is extrapolated that vapor circulation from the operating IC may have maintained the fuel rods at relatively low temperatures. However, the temperature becomes significantly high when the vapor circulation stops owing to the failure of the IC. According to this discussion, certain fuel rods may have been at a high temperature at 20:26 and the high-temperature vapor would have accumulated at the top of the RPV. It can be expected that the temperature of certain rods increased, and a reaction occurred between the zirconium and the water vapor. This abrupt increase in temperature and the gas generation may have caused a small leak on the RPV at 20:26.

The temperature in the RPV may have decreased after the IC started again at 20:30 and the fuel temperature at TAF may have stayed at a relatively low temperature until the IC stopped at 03:00 on March 12. Then, the pressure and temperature in the RPV increased promptly and the breakdown of the fuel core may have started. In this case, the pressure in the RPV is expected to be significantly higher than that estimated in Fig. 13 because the estimated pressure assumes phase equilibrium of the water vapor.
There are only two pressure values that were measured for the RPV after the tsunami attack and before the hydrogen explosion at 15:36 on March 12 . When we examined the pressure data at 20:07 on March 11 the original value was in the range of 6.7-7.3 MPa, as shown in Fig. 13. TEPCO adopted the average value in their reports [16]. The pressure at 02:45 on March 12 was0.901 MPa. TEPCO claimed that this low pressure is an evidence that the IC was not working and the RPV ruptured in the early stage of the accident.

The IC had a sufficiently large cooling performance to cool the decay heat just after the scram. The decay heat at 02:45 was $22 \%$ of the value that was estimated immediately after the scram [7]. As shown in Fig. 13, the pressure in the RPV decreased quickly and became the measured pressure at 02:45. Thus, it was determined that this pressure decrease in the RPV could be achieved if the IC was working.

When the IC stopped at 03:00, the pressure increased significantly quickly. We estimated that the RPV fracture occurred at 6:20 owing to the quick increase in the pressure of the RPV. The blow-in gas from the RPV to the PCV caused the pressure to increase at 06:23.

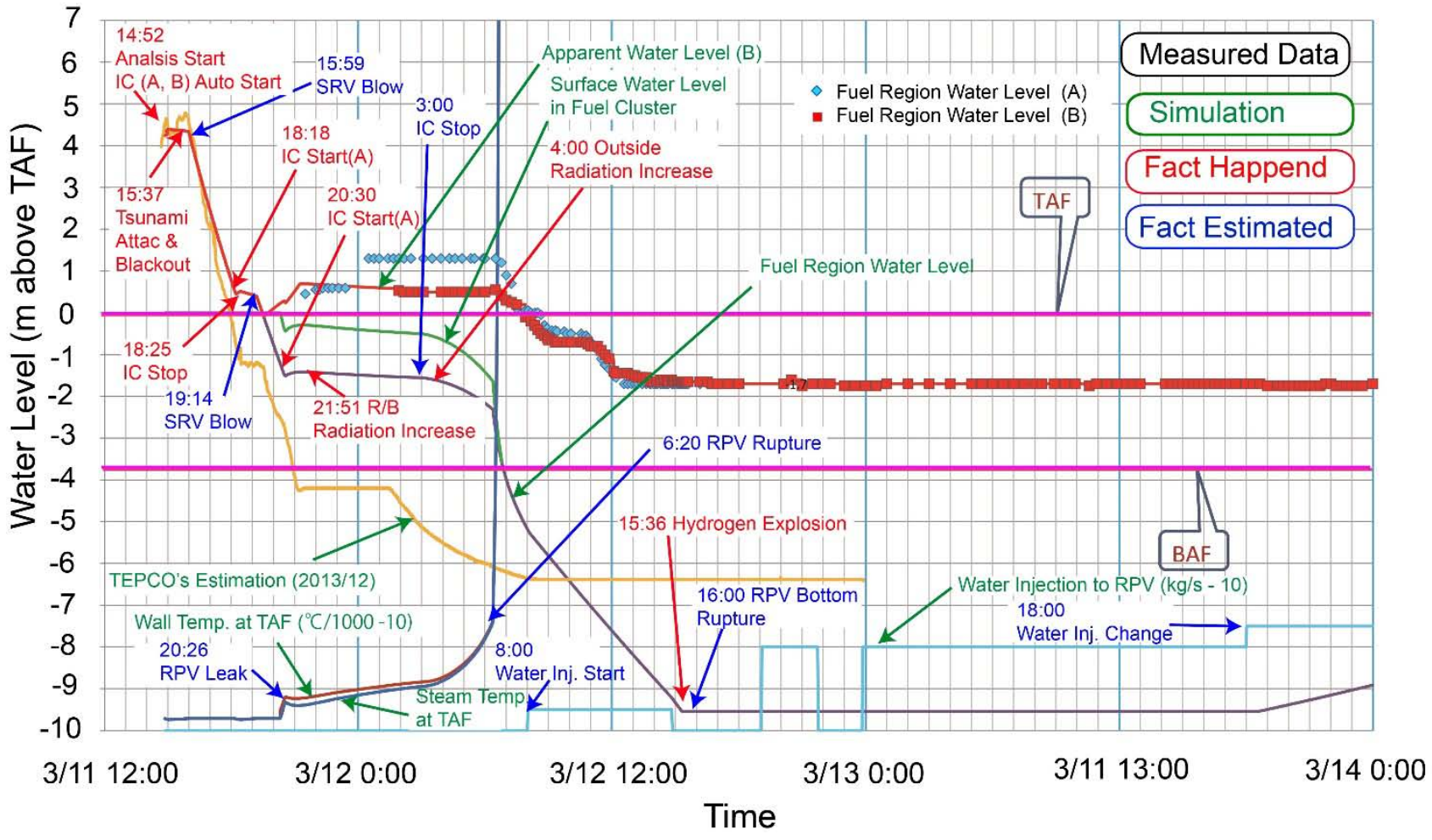

Fig. 14: Estimated water level in the RPV according to the present scenario in comparison with measurements in Fig. 8 and the estimations presented by TEPCO [12]. The present estimation shows the water level was lower than the TAF at 20:26 on 11 March, and a small leakage occurred in the RPV. This explains the radiation increase in the reactor building at 21:51. IC-A was restarted at 20:30, and stopped at 03:00 on March 12. We estimate that the RPV ruptured at 06:20; then, the water level reached the bottom and the fuel leaked out at approximately at 16:00. 


\section{c) Water Levels in RPV}

Figure 14 shows the estimated water levels and measured data from reactor water level meters A and B. According to heat transfer analysis of fuel clusters, the water level in the fuel cluster is higher than the water level outside the shroud when the water level becomes lower than the TAF [HTC Rep.26.2, 2013/03/03], [9].

The water levels (outside the shroud), as estimated by TEPCO [12], and the estimation that the author derived from the heat transfer model in Section $\mathrm{V}$ b and Fig. 12 are also shown in Fig. 14. The upper part of the fuel may have been wet because boiling water inside the fuel cluster expanded owing to the void in the cluster channels. The water level in the cluster channel $Z_{w}$ is also shown in Fig. 14. This can be estimated by the void fraction distribution or quality distribution in the fuel cluster, assuming the cluster is a single pipe with uniform heat flux, as discussed in a previous report [9].

When the IC restarted, as discussed above, the vapor circulation from the operating IC may have kept the fuel rods at relatively low temperatures, even if the water level $Z_{W}$ was below the TAF. When the IC stopped, and the water level in the cluster $Z_{w}$ became lower than the TAF, the fuel surface was covered with pure vapor and the wall temperature increased rapidly. The temperature of the steam and the surface of the fuel rod at the TAF can be estimated by the steam generation rate and forced convection in a pipe [9]. The estimated wall temperatures of the fuel rod and steam at the TAF are shown in Fig. 14.

The estimated rates of water injection to the RPV are shown in Fig. 14. The injection rates are smaller than the reported values, because there is a possibility that the injected water entered the bypass line, and all water may not reach the RPV. The injection rate was adjusted to satisfy the condition that the reconstructed water level meters in Fig. 12 agree with the obtained data [HTC Rep.26.2, 2013/03/03].

In the present estimation, the water level started to decrease at 15:59 on March 11 as the RPV steam was blown down to the S/C by the SRVs. This behavior agrees with the measured data [13]. The decrease in water level stopped when the operators restarted the IC at 18:18. Then, the water level started decreasing again at 19:14 because the IC was stopped at 18:25. The water level reached the TAF at 19:30. At that time, the fuel cluster at the TAF was still wet because the bubbly flow in the fuel cluster maintained saturation temperature at the fuel surface.

When the water level was below the TAF at $20: 26$, the fuel roads at the TAF dried out and hightemperature steam was ejected to the upper part of the RPV. The pressure and temperature of the steam at that time is expected to be significantly higher than the estimation. Moreover, the zirconium-steam reaction may have occurred at that time. It is suspected that the hightemperature steam was ejected through a SV.
When the IC was restarted at 20:30, the water levels in the RPV and fuel cluster were below the TAF. However, it is estimated that the vapor temperature and pressure decreased owing to the circulation of water and vapor through the IC. When the IC was working, stable circulation was maintained until the IC stopped again. This stable water level indicates satisfactory operation of the water level meters, and the measured water level data can be reconstructed as shown in Fig. 12.

TEPCO [12] carried out a simulation of the accident at Unit 1 using the simulation program MAAP. TEPCO estimated an early meltdown due to the nonfunctional IC after the tsunami attack. We performed a simulation based on the same accident scenario that was adopted by TEPCO [9] and obtained approximately identical results for the water level in the RPV as obtained by MAAP. However, the water level estimation by TEPCO [12] could not reconstruct the measured water level data [HTC Rep.32.2, 2014/03/05].

We estimated that the IC stopped at approximately 03:00 on March 12. Then, the temperature of the fuel increased rapidly, as shown in Fig. 14, and the meltdown started. The water level in the RPV decreased quickly because of decompression boiling due to the abrupt pressure decrease at 06:20. The RPV ruptured owing to the high pressure and high temperature of vapor in the upper part of the RPV at 06:20. The vapor ejected to the PCV caused a rapid increase in the size of the ruptured area of the PCV at 06:23. It should be noted that the present thermodynamic model cannot accurately express the behavior of the RPV when the water level is below the TAF. However, the phenomena that occurred can be qualitatively described by adjusting parameters such as the rupture area.

As the pressure in the RPV decreased, water injection started at 08:00, as shown in Fig. 14. At that time, we considered that the thermodynamic equilibrium was somehow maintained owing to the injection of water. The injection rates were smaller than the reported values, because there is a possibility that the injected water entered the bypass line and the entire amount of water may not reach the RPV. The injection rate was adjusted to satisfy the condition that the reconstructed water level meters in Fig. 12 agree with the obtained data.

The reactor water level decreased after the RPV ruptured at 06:20, and it became almost zero at approximately 16:00. The present accident scenario estimated that the RPV ruptured again at that time. TEPCO estimated that the RPV melted down around 22:00 on March 11. This is significantly earlier than our estimation at around 16:00 on March 12. The molten fuel may have spilled out from the bottom of the RPV; however, this scenario estimates that a large portion of 
the fuel remains in the RPV to date. The reasons for this estimation are discussed in the subsequent section.

\section{Vil. Prediction of Rupture Times and POSITIONS}

From the previous discussion, it is possible to explain the measurement data, activity records, and eyewitness testimonies of the workers at that time, if the IC is assumed to be working for a certain period of time after the tsunami attack. The accident scenario listed in Table 2 can explain, to some extent, the pressure data, water levels, and radiation intensities of the RPV and PCV, which were measured at the time of the accident.

We estimated that at 20:26 on March 11, a crack with an equivalent diameter of $1.7 \mathrm{~cm}$ occurred in the RPV and steam was ejected into the D/W. At 03:30 on March 12, the PCV was damaged and its equivalent diameter was 3.5-3.7 cm. At 06:20, the RPV was damaged and a large amount of steam was ejected into the D/W. The equivalent diameter of the damaged part of the RPV was $7 \mathrm{~cm}$. The water in the RPV ran out and the molten fuel leaked from the bottom of the RPV into the pedestal of the PCV at approximately at 16:00. The time of fuel leakage was significantly later than that presented in the evaluation by TEPCO, and we estimated that a significant fraction of the fuel remained in the RPV. Subsequently, when the water injection stabilized, the cracks at the bottom of the RPV were blocked by water and molten fuel, and steam continued to leak from the cracks at the upper part of the RPV.

We estimated the location of the rupture on the PCV [HTC Rep.25.1, 2012/12/26], [9], and we presumed that the location of the rupture was at the bellows that connects the D/W and the S/C. TEPCO examined the interior of the $\mathrm{R} / \mathrm{B}$ and estimated that the rupture occurred at the bellows near the bottom of the D/W and vacuum breaker tube [13]. This position is considerably close to our estimated position [HTC Rep.25.1, 2012/12/26].

Between March 20 and 22, 2011, there was a period of time when the water injection rate into Unit 1 was significantly low. This decrease in water injection resulted in the temperature of the entire reactor reaching approximately $400^{\circ} \mathrm{C}$. After March 23, the water injection volume increased and the temperature inside the reactor rapidly dropped. Electric power was restored to the central control room after March 20, and temperature data from various parts of the reactor was finally obtained.

By examining the temperature data of each part of the reactor, it is possible to estimate the condition of the reactor after the accident and the damaged parts to a certain extent. However, the exact locations of the temperature sensors and the reactor components are not known at this time. It is important to understand that there are a number of uncertainty factors involved in such estimations. This analysis is based on public data; however, it is expected that there are several unpublished reports that are not available to the author. It is possible that the present estimation may not be accurate when those data become available.

In this section, the author attempts to present bold predictions regarding the positions and times of vessel ruptures according to the present accident scenario listed in Table 2. These predictions may change based on different accident scenarios, and the present predictions may not be accurate. However, to contribute to the nuclear reactor accidents in the future, we will attempt to estimate the locations and times of the ruptures in the RPV and PCV without fear of being accused of inaccuracy.

\section{a) Identification of Temperature Measurement Points}

TEPCO released the temperature measurement data of each part of the reactor after March 20, 2011, and in the Microsoft Excel format on May 17 [29]. Table 3 lists the "List of plant data collected by the operator during the accident" [30] and the locations and names of the temperature data that were measured immediately after the accident, as estimated from various public data. Based on these data, it is possible to estimate the locations and names of the temperature data measured immediately after the accident. The temperature measurement points of each part of the reactor were estimated and are shown in Figs. 15 and 16.

The position of the water supply nozzle is important; however, the exact location is unknown. Further, there is no precise information regarding the location of the temperature sensors of the SV and SRV, and the direction in which the SV blows out the steam. If this information was available, the accuracy of the estimation would increase. 
Table 3: List of temperature data collected by the operator during the accident

\begin{tabular}{|c|c|c|c|c|c|c|}
\hline $\begin{array}{l}\text { TC } \\
\text { No. }\end{array}$ & Name & Tag. No & Service Name & Position & Direction & Height \\
\hline 20 & Vessel Flange & TE-263-66B1 & Vessel Head Flange & RPV & 270 & 33000 \\
\hline 21 & $\begin{array}{c}\text { Vessel Flange(Vessel } \\
\text { Stream) }\end{array}$ & TE-263-67A1 & Vessel Stud & RPV & 270 & 33000 \\
\hline 22 & $\begin{array}{c}\text { Water Supply Nozzle N4B } \\
\text { (Terminal) }\end{array}$ & TE-263-69D1 & N4B Nozzle End & RPV & 135 & 27750 \\
\hline 23 & $\begin{array}{c}\text { Water Supply Nozzle } \\
\text { N4B(Inner) }\end{array}$ & TE-263-69D2 & $\begin{array}{l}\text { N4B Nozzle End } \\
\text { Inboard }\end{array}$ & RPV & & \\
\hline 24 & $\begin{array}{c}\text { Water Supply Nozzle } \\
\text { N4C(Terminal) }\end{array}$ & TE-263-69E1 & N4C Nozzle End & RPV & 225 & 27750 \\
\hline 25 & $\begin{array}{c}\text { Water Supply Nozzle N4C } \\
\text { (Inner) }\end{array}$ & TE-263-69E2 & $\begin{array}{l}\text { N4C Nozzle End } \\
\text { Inboard }\end{array}$ & RPV & & \\
\hline 26 & Vessel Core & TE-263-69F3 & Vessel Core & RPV & 270 & 22160 \\
\hline 27 & $\begin{array}{c}\text { RPV Lower Part (Lower } \\
\text { Head) }\end{array}$ & $\begin{array}{c}\text { TE-263-69L1 or } \\
\text { 69L2 }\end{array}$ & Vessel Bottom Head & RPV & 25 or 130 & 1550 \\
\hline 28 & $\begin{array}{c}\text { Control Rod Drive (CRD) } \\
\text { Upper Housing }\end{array}$ & TE-263-69N1 & $\begin{array}{l}\text { CRD Housing } \\
\text { Top Edge }\end{array}$ & RPV & & \\
\hline 29 & CRD Lower Housing & TE-263-69N3 & $\begin{array}{c}\text { CRD Housing Top } \\
\text { Edge }\end{array}$ & RPV & & \\
\hline 30 & $\begin{array}{l}\text { SV Exhaust } \\
\text { 203-4A(1) }\end{array}$ & TE-261-13A & SV-4A & PCV $(D / W)$ & & \\
\hline 31 & $\begin{array}{l}\text { SV Exhaust } \\
203-4 C(2)\end{array}$ & TE-261-13C & SV-4C & PCV (D/W) & & \\
\hline 32 & $\begin{array}{l}\text { SV Exhaust } \\
203-4 \mathrm{~B} 3\end{array}$ & TE-261-13B & SV-4B & $\mathrm{PCV}(\mathrm{D} / \mathrm{W})$ & & \\
\hline 33 & $\begin{array}{l}\text { SRV Exhaust } \\
\text { 203-3A6 }\end{array}$ & TE-261-14A & $\begin{array}{c}\text { RV-203-3A (Blowdown } \\
\text { Valve) }\end{array}$ & PCV $(\mathrm{D} / \mathrm{W})$ & & \\
\hline 34 & $\begin{array}{l}\text { SRV Exhaust } \\
\text { 203-3B(7) }\end{array}$ & TE-261-14B & $\begin{array}{c}\text { RV-203-3B } \\
\text { (Blowdown Valve) }\end{array}$ & $\mathrm{PCV}(\mathrm{D} / \mathrm{W})$ & & \\
\hline 35 & $\begin{array}{l}\text { SRV Exhaust } \\
\text { 203-3C8 }\end{array}$ & TE-261-14B & $\begin{array}{c}\text { RV-203-3C } \\
\text { (Blowdown Valve) }\end{array}$ & PCV (D/W) & & \\
\hline 36 & $\begin{array}{l}\text { SRV Exhaust } \\
\text { 203-3D 9) }\end{array}$ & TE-261-14B & $\begin{array}{l}\text { RV-203-3D (Blowdown } \\
\text { Valve) }\end{array}$ & $\mathrm{PCV}(\mathrm{D} / \mathrm{W})$ & & \\
\hline 39 & $\mathrm{HVH}-12 \mathrm{CReturn}$ & TE-1625C & $\begin{array}{l}\mathrm{HVH}-12 \mathrm{C} \\
\text { Return Air }\end{array}$ & $\mathrm{PCV}(\mathrm{D} / \mathrm{W})$ & & \\
\hline 41 & $\begin{array}{c}\text { RPV Bellow Seal }(H V H-12 A \\
1625 L) \\
H V H-12 A ?\end{array}$ & TE-1625A & $\begin{array}{l}\mathrm{HVH}-12 \mathrm{~A} \\
\text { Return Air }\end{array}$ & $\mathrm{PCV}(\mathrm{D} / \mathrm{W})$ & & \\
\hline 43 & S/C Pool Water & & & $\mathrm{PCV}(\mathrm{S} / \mathrm{C})$ & & \\
\hline
\end{tabular}




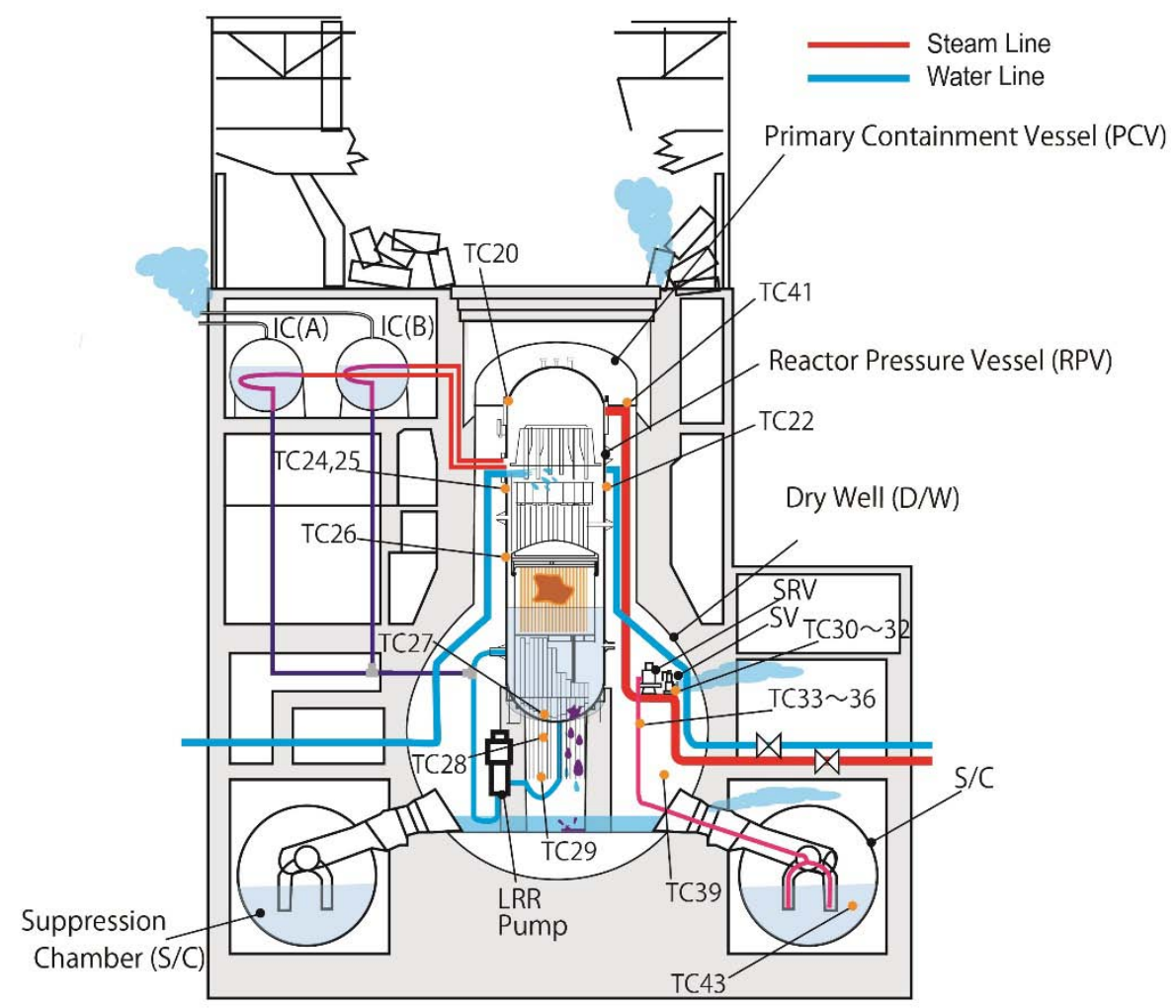

Fig. 15: Cross section of the reactor and estimated location of the position of the thermometer

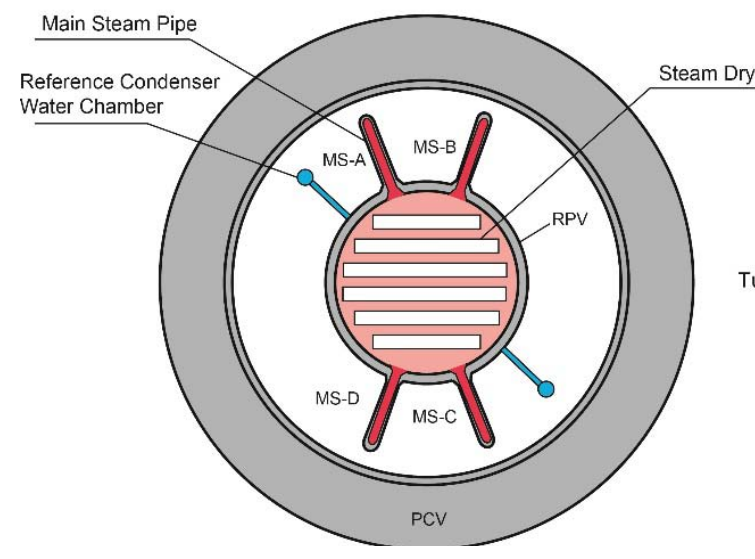

(a) Reactor core around the main steam pipe (Cross section at TAF $+5.64 \mathrm{~m}$ )

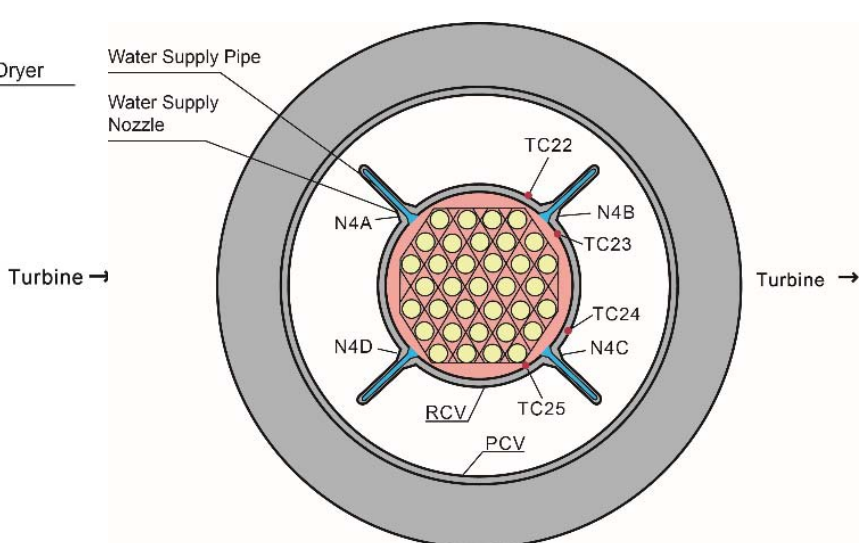

(b) Reactor core around the water supply pipe (Cross section at TAF -2.18m) 


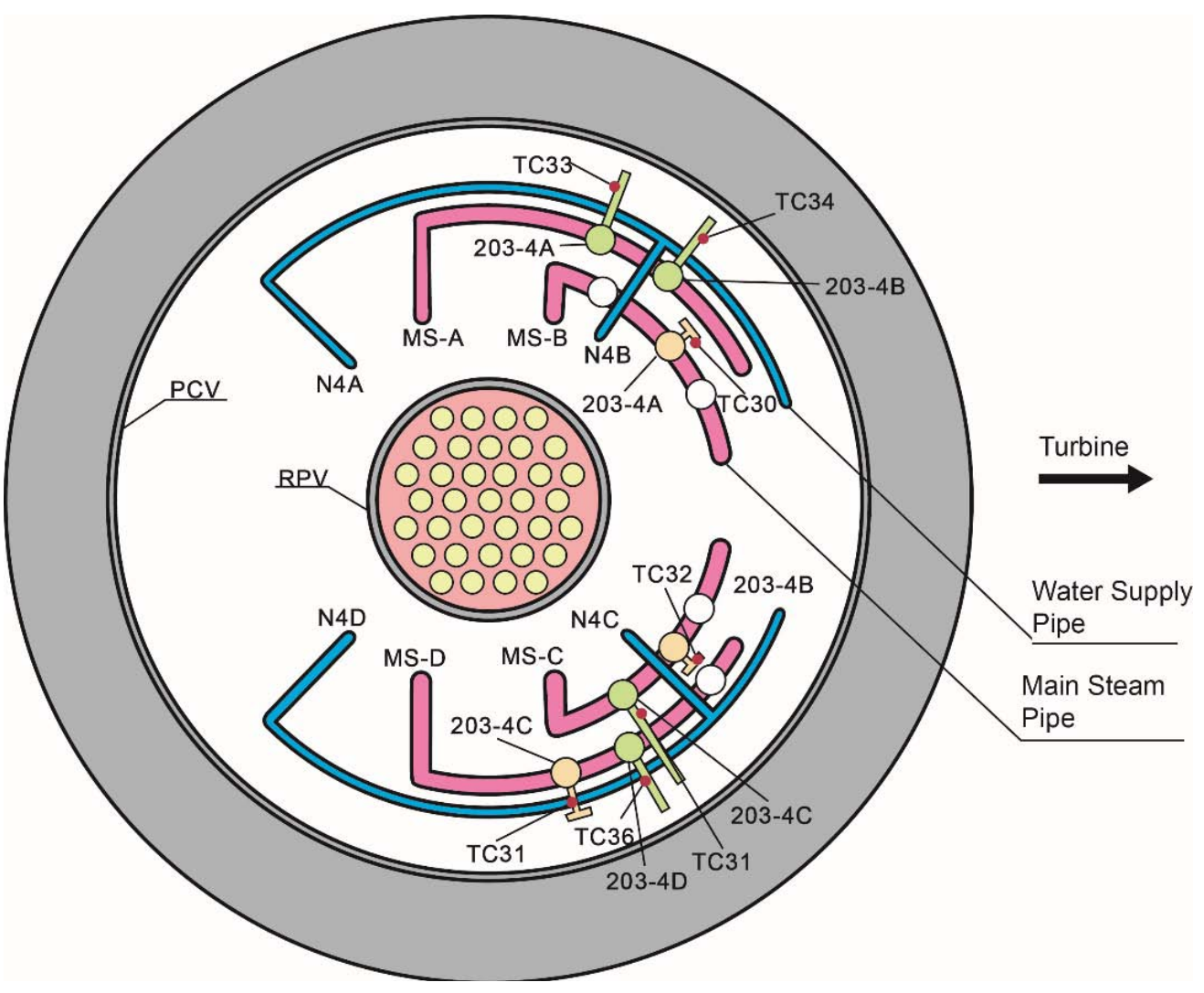

(c) Temperature measurement positions around SV and SRV

Fig. 16: Reactor cross section and estimated temperature measurement points at each height

Figures 15 and 16 show the locations of the temperature measurement points in the reactor, as estimated by the author. The exact locations of the temperature measurement points and the details of the reactor structure are not published. The positions of the temperature measurement points in Figs. 15 and 16 were estimated using the data listed in Table 3 and various published data. Therefore, these positions may differ from the actual positions. The numbering of the temperature measurement points shown in Figs. 15 and 16 corresponds to the numbers listed in Table 3 .

Figure 16(c) describes the estimated locations of the SRV and SV installed in Unit 1. Both valves were installed on the main steam pipe. The steam released from the SRV was condensed with water in the S/C. However, the steam released from the SV was ejected directly to the $\mathrm{D} / \mathrm{W}$. Therefore, the pressure in the PCV may rise rapidly when the SV is activated. The pressurerelease setting of the SV is higher than that of the SRV. According to the attachment of the interim report published by TEPCO [31], the working pressure of the SRV ranges from 7.27 to $7.71 \mathrm{MPa}$, while the working pressure of the SV ranges from 8.51 to $8.62 \mathrm{MPa}$; consequently, the SV is not activated under normal operating conditions. However, the SV may be activated when the water level in the RPV drops below the TAF and the pressure increases rapidly, as is the case when the steam-zirconium reaction occurs. 
b) Evaluation of Temperature Data

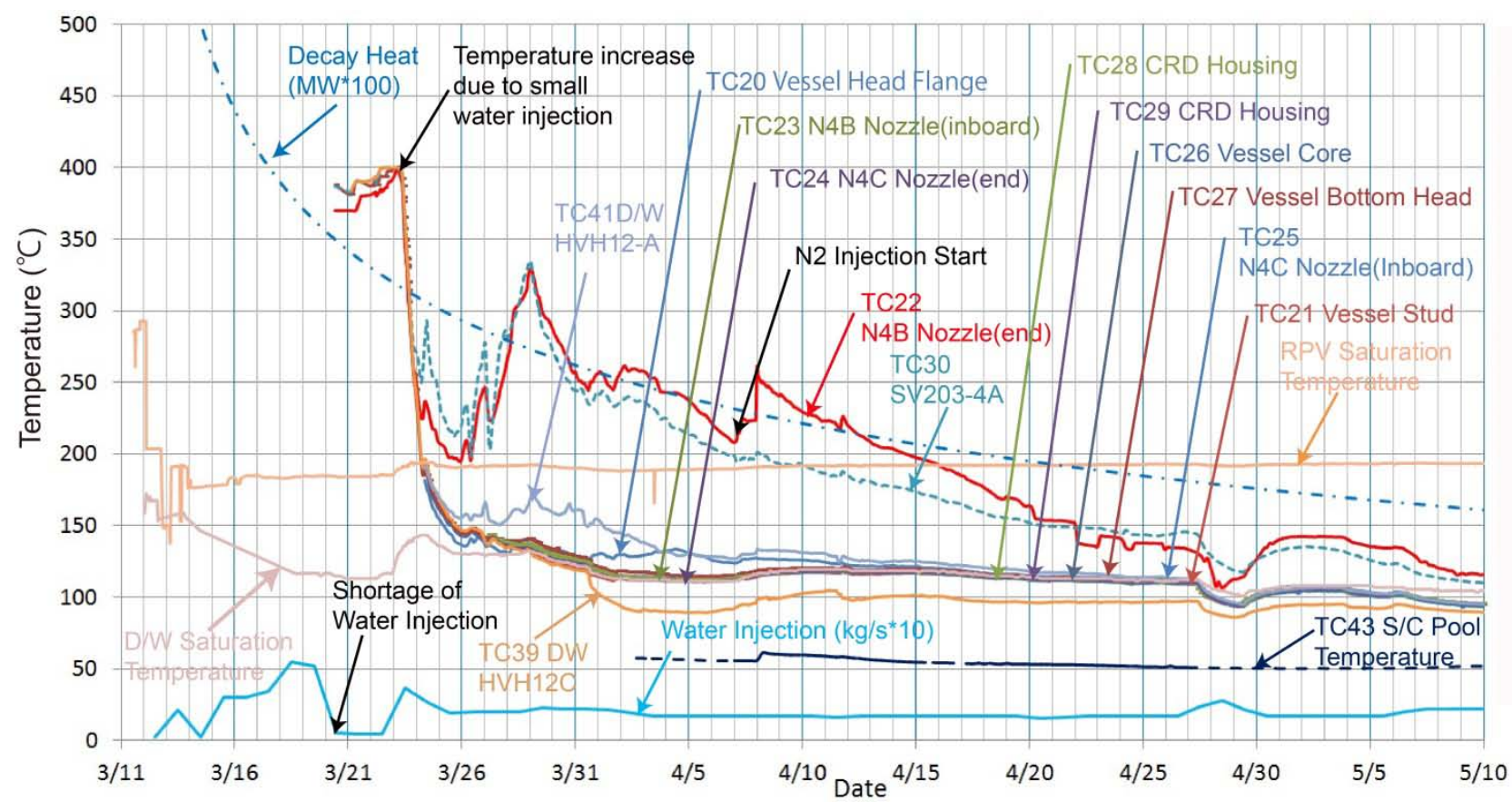

(a) Temperature changes around RPV and PCV

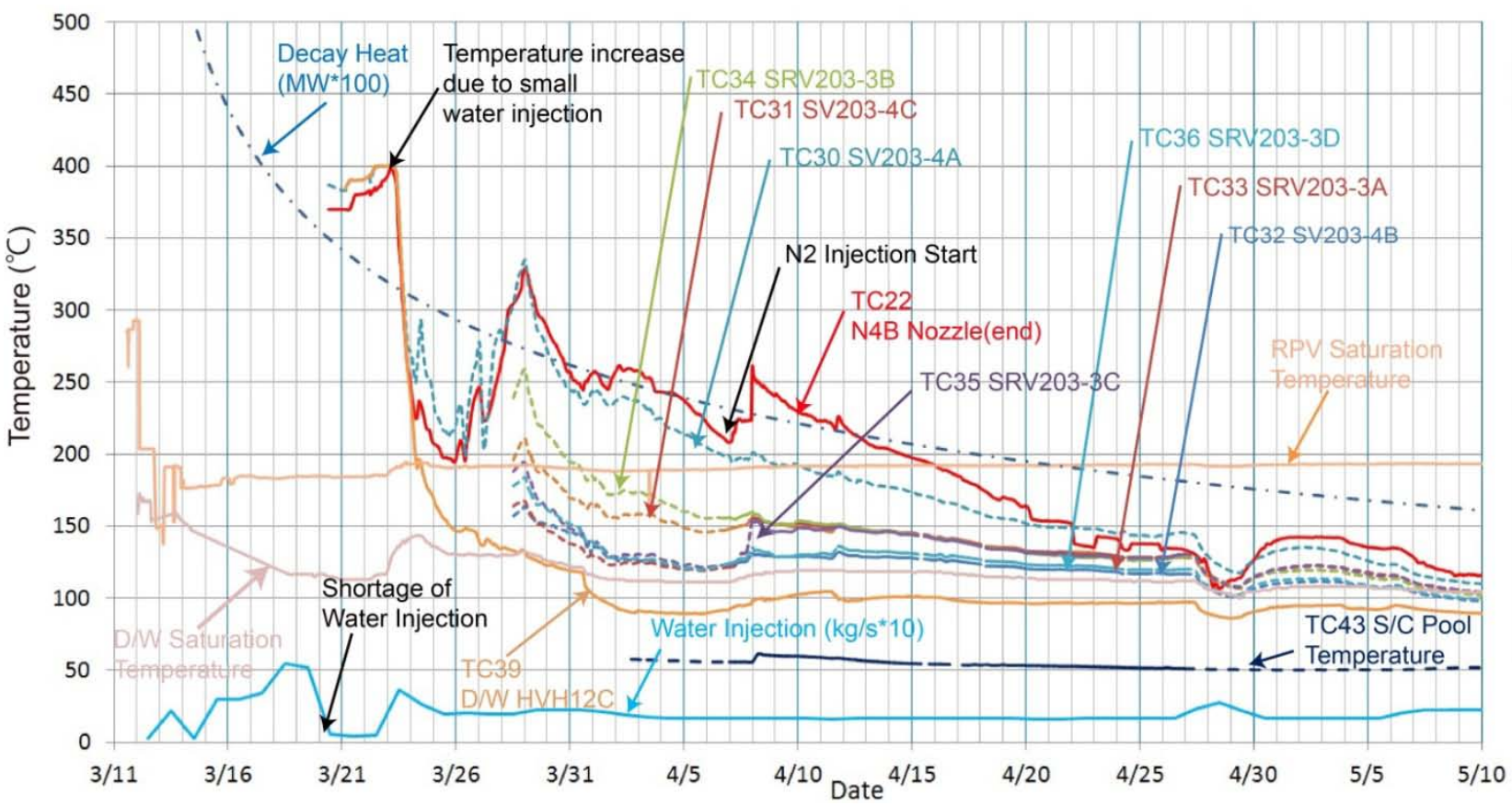

(b)Temperature changes around SV and SRV

Fig. 17: Temperature changes in various parts of the reactor, water injection rate, decay heat rate, and saturated steam temperature after March 20, 2011

As mentioned above, the amount of water injected into Unit 1 was significantly reduced from March 20 to 22, and the temperature in various parts of the reactor reached $400^{\circ} \mathrm{C}$. Then, the amount of water injected into the reactor core increased, resulting in a rapid decrease in the temperature inside the reactor. Figure 17 shows the temperature changes in each part of the reactor that could be measured after March 20 . The temperature measurement points are listed in Table 3 and illustrated in Figs. 15 and 16. The record of water injection volume at that time and the change in decay heat are shown in Fig. 17. The saturated vapor temperatures calculated from the RPV and D/W pressures are also depicted. 
Figure 17 shows that the temperature of each part of the reactor increased and became almost uniform owing to the extreme decrease in water injection from March 20 to 22. After the water injection rate was stabilized in April, the temperature of each part of the reactor gradually decreased with the decrease in the decay heat.

First, let us compare the temperature measurement position in Fig. 15 with the temperature change in Fig. 17(a). It should be noted that the temperature at the bottom of the RPV (TC27) decreased simultaneously with the water injection and became equal to the saturation temperature of the $\mathrm{D} / \mathrm{W}$. The temperature of the control rod drive housing in the PCV, which is called the control rod drive (CRD), (TC28 and TC29) was also at the saturation temperature of the $\mathrm{D} / \mathrm{W}$. Conversely, the end of the water supply nozzle N4B (TC22) and SV 203-4A (TC30) remained hot and their temperatures were higher than the RPV saturation temperature. The end of the feed water nozzle N4C (TC24) was at the same temperature as the bottom of the reactor. This suggests that the water supply was coming from here, and the temperature was low.

Let us assume that most of the fuel rods have melted out of the RPV into the PCV and accumulated in the pedestal at the bottom of the PCV, as TEPCO estimates. Water injection would flow from the feed water nozzles into the RPV and flow out of the bottom of the RPV to cool the fuel deposited in the PCV. Therefore, the temperature of the D/W with the heat source should be higher than the temperature inside the RPV. However, the measurement result indicated the opposite. Furthermore, the temperature inside the D/W (TC39) was lower than the saturation temperature of the $\mathrm{D} / \mathrm{W}$. The phenomena estimated by TEPCO is unlikely because the $D / W$ is filled with high-temperature vapor when most of the fuel is discharged into the PCV.

By assuming the accident scenario of this report, as listed in Table 2, the injected water leaked out from the hole at the bottom of the RPV, which was formed at approximately at 16:00 on March 12 . Conversely, the superheated steam generated by the fuel in the RPV leaked out from the crack in the gas phase. These phenomena explain the temperature changes shown in Fig. 17(a). The fractures in the RPV were formed at approximately at 10:26 on March 11 and at 06:20 on March 12. As the water injection into the RPV has been stable since March 23, it is presumed that the water that saturated in the RPV leaked out from the lower part of the RPV. The water caused the lower part of the RPV and the D/W of the RPV to have homogeneous temperatures.

Next, the thermometer arrangement in Fig. 16(c) is compared with the reactor temperature data in Fig. 17(b). If the SV (203-4A), which is connected to the main steam pipe of system $B$, was damaged and continued to discharge steam, it can be explained that the thermometer at the end of the feed water nozzle N4B (TC22) and the temperature data of SV 203-4A (TC30), which is installed near the main steam pipe of system $B$ in the RPV, showed prominently high temperatures.

Conversely, the temperature of the end of the feed water nozzle N4C (TC24) in Fig. 17(a) is cold at the same time, when the water injection restarted. This suggests that water injection to the core was performed through nozzles N4C and N4B immediately after the accident; however, the authors do not have detailed data regarding this. The inner thermometer (TC23) of nozzle N4B is also at a low temperature. As the detailed locations of the thermometers are not known, further investigation is required to determine these phenomena.

While considering the SV and SRV temperatures, SRV203-3B (TC34) near SV203-4A (TC30) showed a high temperature. One possibility is that the steam that leaked from SV203-4A hit the temperature measurement point of SRV203-3B, and TC30recorded a high temperature. Conversely, the high-temperature steam have been released from the SRV to the S/C at approximately 06:20 on March 12 . It is also possible that the steam damaged the valve seat of SRV203-3B at that time, and the steam continued to leak from the SRV after March 23.

As for the SVs, SV203-4C (TC31) recorded the second-highest temperature after SV203-4A. If the steam that leaked at 20:26 on March 11was caused by the valve seat damage of this SV, the temperature change of TC31 can be understood. The SRV (SRV2033B) showed temperatures higher than the saturation temperature of the D/W. It is possible that the valve seat of the SRV was damaged by the hot steam leak at 06:20 on March 12, as shown in Figure 14, and the leak continued.

It will be a long time before the SV and SRV are retrieved and inspected; therefore, this assumption cannot be clarified until further investigations are performed. It may not be possible to ever identify the locations of the RPV leaks.

\section{c) Estimation of Fracture Status based on Temperature Data}

In the interim report document presented by TEPCO [31], the operating pressures of the SVs and SRVs are shown; however, the pressure values that are set for the operation of each valve are not stated. Therefore, assuming that the accident scenario in this report is correct, the estimated valves and estimated operating pressures are listed in Table 4. According to this accident scenario and Figure 17(b), the pressures set for the operation of SV203-4C and SV203-4A must be lower than that of SV203-4B for the valve seat of SV203-4C to become stuck at 20:26 on March 11 owing to the high-temperature steam and for SV203-4A to be damaged at 06:20 on March 12. 
As mentioned earlier, the seat of the SRV (SRV203-3B) may have also become stuck at this time. The temperature of SRV203-3C increased marginally after the injection of nitrogen; therefore, the operation pressure was estimated to be lower than SRV203-3A and SRV203-3D. If the estimated value and the actual valve setting operating pressure are the same, the accuracy of this accident scenario will increase.

According to the estimation in this report, the SVs may have been activated owing to the rapid pressure increase and dry out of the fuel rods after 20:26 on March 11 and 03:00 on March 12. As shown in Fig. 14, it is presumed that the steam stored in the upper part of the vessel was significantly hot when the RPV was destroyed. At that time, it cannot be excluded that the valve seat and other parts of the SVs were damaged, and the valve was maintained in an open condition. In general, the maximum operating temperature of the SRV is $302{ }^{\circ} \mathrm{C}$, and the maximum operating temperature of the other valves are $550{ }^{\circ} \mathrm{C}$. Because zircaloy reacts with steam above a temperature of $900^{\circ} \mathrm{C}$, it is likely that steam at a temperature considerably higher than the maximum operating temperature passed through the SVs and SRVs.

Table 4: Estimation of operating pressures for safety valves and safety relief valves

\begin{tabular}{|c|c|c|}
\hline Type of Valve & Name in Fig. 16(c) & $\begin{array}{c}\text { Operating } \\
\text { Pressure (MPa) }\end{array}$ \\
\hline Safety Valve (SV) & 203-4A, 203-4C & 8.51 \\
\hline Safety Valve (SV) & 203-4B & 8.62 \\
\hline $\begin{array}{c}\text { Safety Relief } \\
\text { Valve (SRV) }\end{array}$ & 203-3B, 203-3C & 7.64 \\
\hline $\begin{array}{c}\text { Safety Relief } \\
\text { Valve (SRV) }\end{array}$ & 203-3A, 203-3D & 7.71 \\
\hline
\end{tabular}

Based on the accident scenario of this report, and considering Figs. 13 and 14 and the aforementioned discussion, and making a bold prediction, the destruction scenario for Unit 1 is estimated to be as follows.

1. At approximately 20:26 on March 11, hightemperature steam from the RPV passed through the SV and circulated into the D/W.As the valve seat of SV203-4C was stuck, the steam blew out through a rupture with an equivalent diameter of $1.7 \mathrm{~cm}$.

2. The leaked contaminated gas from the RPV was stored in the PCV, resulting in an increase in the radiation in the $R / B$ at that time. Accordingly, entry to the $R / B$ was prohibited at 21:51.

3. The PCV pressure increased owing to this steam discharge, and at approximately 03:30 on March 12 a crack with an equivalent diameter of $3.5 \mathrm{~cm}$ occurred in the bellows of the vacuum break valve connecting the D/W and S/C in the lower part of the PCV.
4. The radiation level at the main gate increased after 04:00 due to the contaminated gas that released from the PCV to the environment.

5. The temperature and pressure of the RPV increased rapidly due to the $\mathrm{IC}$ shutdown at approximately 03:00; moreover, the valve seat of the SV (SV2034A) was stuck at 06:20, resulting in a rupture with 7 $\mathrm{cm}$ diameter.

6. At approximately at $06: 23$, the crack at the bottom of the PCV widened or a new crack appeared. The size of the crack was equivalent to $8 \mathrm{~cm}$ in diameter. There is a possibility that the PCV was damaged again in addition to the crack at the bellows of the vacuum break valve.

7. The water in the RPV was running out, and the R/B experienced a hydrogen gas explosion at 15:36, resulting in the cessation of water injection. Moreover, at approximately at 16:00, a hole was created at the bottom of the RPV and the molten fuel was discharged. However, a significant fraction of the fuel is considered to have remained in the RPV.

For the estimation of the location of the destruction, it is essential to obtain a more detailed structure of the reactor and accurate information such as the location of the temperature sensors and the location of the SVs and SRVs. However, this information was not available at the time of writing this report. If this information can be obtained in the future, it will be possible to estimate the damage location with a higher degree of accuracy. The estimated failure location may change when the detailed reactor structure becomes known.

To contribute to the internal investigation of the PCV and RPV to be conducted in the future, the status inside the RPV can be estimated based on the accident scenario in this report. However, this is only a bold estimation; moreover, it is quite possible that the current accident scenario will be completely different when new information becomes available. 


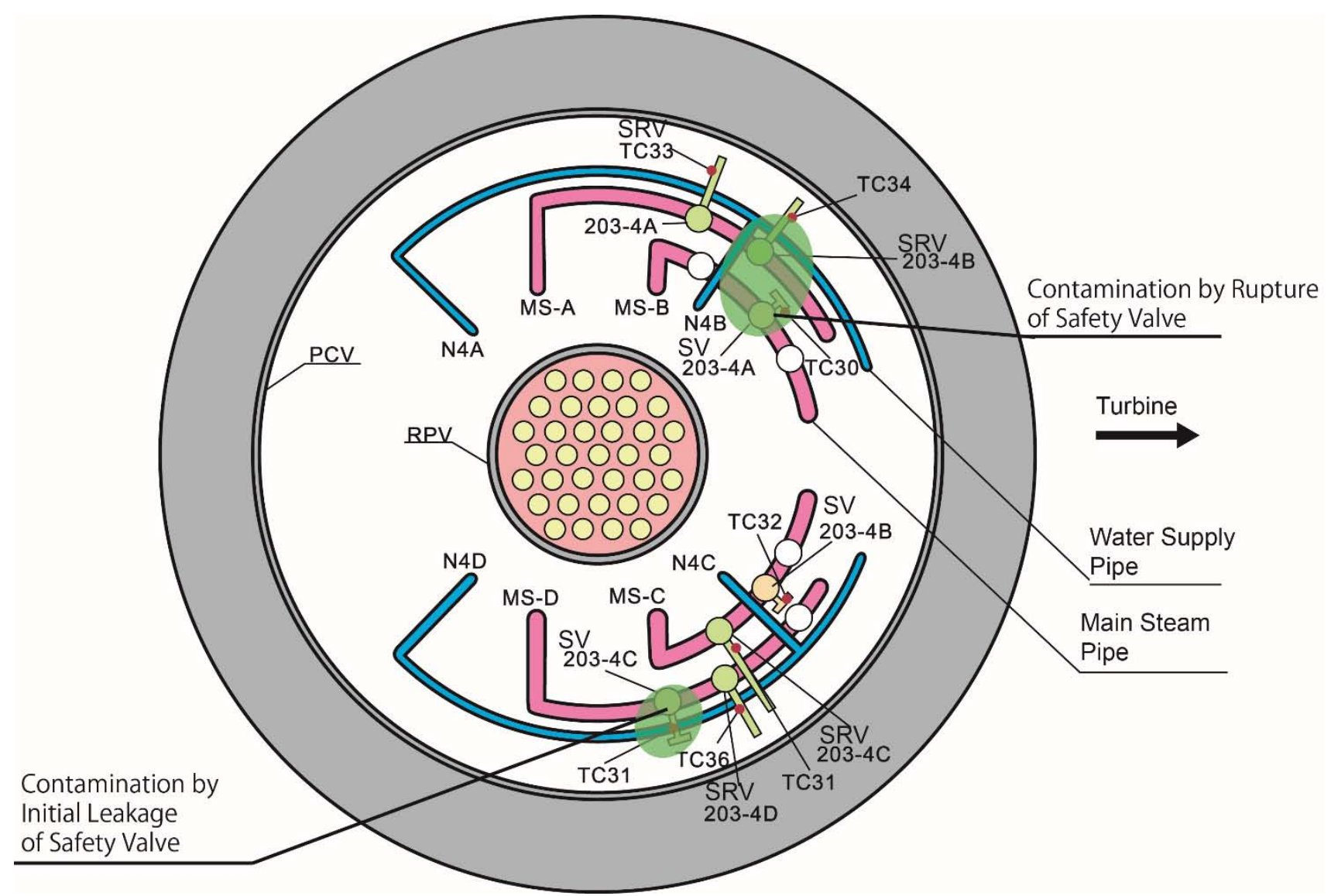

Fig. 18: Estimation of high radiation points in the PCV

Figure 18 shows the location where the radiation intensity is estimated to be high owing to this accident scenario. We estimate that the largest leak occurred at the safety valve, SV203-4A (TC30) at around 06:20. The leaked steam might have been ejected to TC34. Because the SRV valve seat is also considered to be damaged to a certain extent, the radiation intensity of the piping near the SRV (RV203-3B) is considered to be high. The next area that was considered to be contaminated is near the release port of SV203-4C (TC31). This leakage is estimated to have occurred at 20:26 on March 11.Asthe area of this leak was smaller than that of SV203-4A, the degree of contamination is not significantly large. A hole was formed at the bottom of the RPV at approximately 16:00 on March 12, and the injected water probably leaked out from there.

If the estimation in this report is accurate, the water level in the RPV decreased below the TAF, and hot water vapor and hydrogen gas were generated; the leaked high-temperature gas resulted in sticking of the seat of the SV. The BWR is not designed for the water level to decrease below the TAF; however, the risk of the reactor water level falling below the TAF and the resulting hot gas destroying the SV must be considered, as in the Fukushima Daiichi NPP accident. If the materials of the valve seat and spring of the SVs are manufactured to withstand high temperatures, operational difficulties such as the gas tightness of the valve are also expected to arise. However, to ensure the safety of the reactor, certain operational difficulties may be acceptable.

At the Fukushima Daiichi NPP, two emergency diesel generators were installed on the same floor for operational simplicity. Neither of these emergency systems functioned when the tsunami entered the R/B. Although operational difficulties are expected to arise, to prevent future accidents at NPPs, it is considered necessary to improve safety when the reactor water level decreases below the TAF.

\section{Vili. Conclusions}

To prevent future nuclear accidents, the accident at Fukushima Daiichi NPP must be properly analyzed and understood. We had been analyzing the accident since its occurrence [2]. According to the original records and witnesses, we verified that the IC of Unit 1 of the Fukushima Daiichi NPP may have been working normally to a certain extent. Based on this assumption, we performed an accident analysis based on the accident scenario. Moreover, the behavior of the reactor water level meter at the time of the accident was analyzed, and this study attempted to reproduce the measurement data of the reactor water level meter during the accident. To contribute to the investigation of 
nuclear accidents in the future, we attempted to estimate the failure locations and failure times of the RPV and PCV without fear of being accused of inaccuracy.

The predictions of the accident analysis have many possibilities under the different accident scenarios; moreover, the present predictions may not be accurate. However, there was only one true event of the accident that really happened.

The results obtained from the analysis are as follows:

1. The original data reported in the first stage of the accident and the evidence obtained from the operators were examined to clarify the behavior of the ICs. There are records that the water injection to the reservoir tank of IC-A was executed. There was a possibility that MOVs were open during the tsunami attack, and that IC-A was working after the tsunami attack until approximately 03:00 on March 12, 2011.

2. The present accident scenario estimated that the initial RPV leak occurred at 20:26 on March 11 and the pressure in the PCV increased because the steam and gas from the RPV were directly blown into the D/W. This scenario agrees with the increase in radiation intensity that was recorded in the $R / B$ at 21:51. Owing to the increase in the PCV pressure, the PCV ruptured at approximately 03:30 and 06:23 on March 12 at the bellows of the vacuum breaker tube connecting the $\mathrm{D} / \mathrm{W}$ and $\mathrm{S} / \mathrm{C}$. This estimation agrees with the radiation dosage and pressure data obtained during the accident.

3. It is estimated that the RPV ruptured at 06:20 on March 12 in the vapor phase of the vessel after the IC stopped functioning. The RPV ruptured again at approximately 16:00 at the bottom of the vessel, because the water dried out. Molten fuel may have spilled out to the PCV; however, the amount of fuel that melted was not as large as reported by TEPCO. This estimation agrees with the temperature data measured immediately after the accident and the radiation-dose data measured in the NPP.

4. The author attempted to present bold predictions of the positions and times of vessel ruptures according to the present scenario at the accident site and the temperature data in the reactor, which were obtained after March 20. The temperatures of Unit 1 increased up to $400^{\circ} \mathrm{C}$ on March 22, and they gradually decreased with the increase in injection water. We examined the details of the temperature data that high temperatures were recorded at several locations after water injection. Thus, we concluded that the leakages from the RPV at 20:26 on March 11 and 06:20 on March 12 occurred at the $\mathrm{SV}$, because the significantly high-temperature steam that passed through the valve destroyed the valve seat. Some of the SRVs may have suffered the same process.

\section{iX. Epilogue}

It is difficult to predict the phenomena of a serious accident in real time. At the beginning of an accident, only limited data is available, and even that data is often inaccurate. The accident scenarios that are estimated from these data may be different from the truth.

During the Apollo 13 accident in 1970, the teamwork between the astronauts and the ground group resulted in the miraculous survival of the astronauts. The subsequent investigation, at least as far as the author knows, was conducted quickly and fairly, and not long after, the subsequent set of astronauts landed on the moon.

The star probe Hayabusa, which landed on the asteroid Itokawa in 2005, failed at its first landing. Based on the analysis results from that time, the landing was retried. The team on Earth estimated the conditions of Hayabusa based on the intermittent and insufficient information sent from Hayabusa and took appropriate action.

At the time of the accident at the Fukushima Daiichi NPP in 2011, Units 1-4 of the plant were only less than a kilometer away from the seismically isolated critical building where the headquarters of the task force were located; however, adequate data were not obtained. The case where the operators could not reach to the object was similar to that of Hayabusa, which stayed on the asteroid Itokawa, 300 million kilometers away from the Earth.

When faced with a serious accident, it is important to respond to the incident with flexible thinking according to the situation, similar to the actions of the Hayabusa and Apollo 13 teams. In the case of the accident at the NPP, I wonder if the concerned personnel were able to analyze and respond appropriately to the situation with a clear and flexible mind.

During the Fukushima Daiichi NPP accident, it was initially impossible to get an accurate understanding of the reactor status. Even the wrong data at the time of the accident can be corrected based on reasonable explanations to derive accident scenarios that are closer to the truth. Furthermore, by considering the new data obtained from the internal investigation of the reactor, it is possible to clarify the scenario of the accident more accurately.

Ten years after the accident, it is now possible, to a certain extent, to present scenarios that are closer to the truth of the accident. However, from the perspective of exploring events from the still limited data, elucidating the accidents at NPPs is somehow similar to archeology, where we look at dinosaur fossils 
and attempt to deduce the life trends of dinosaurs that lived 150 million years ago.

It is our duty as scientists and engineers to clarify the real phenomena of the nuclear accident, and to present suggestions for the prevention of nuclear accidents that will occur in the future. We must not distort the historical facts of the nuclear accident for the sake of the reputation of the academician, appearances of the academic community, or the interests of the organization. Several academic societies and organizations have published many reports on nuclear accidents. I wonder if these reports are the result of sincere discussions among scientists and engineers on all possibilities and an attempt to deduce the truth.

In the current situation where we do not know the condition inside the reactor, there are numerous possibilities for nuclear accident scenarios. The accident scenarios in this report can explain the data and events at the time of the accident relatively well. However, I do not believe that all estimates and accident scenarios are accurate. There is only one true event that actually occurred during the nuclear accident. In the future, it is necessary for scientists and engineers to get closer to the truth by conducting serious discussions with each other.

It is important to understand the actual events that occurred at the Fukushima Daiichi NPP. An accurate understanding of the phenomena should contribute to the early termination of the nuclear accident, and prevent similar accidents from occurring in NPPs around the world. Japan, which has suffered a significant amount of human, financial, and cultural damage, should take the leadership in providing the world with accurate accident analysis and guidelines for preventing its recurrence.

\section{ACKNOWLEDGMENTS}

I would like to express my gratitude to colleagues and professors of academic societies who provided me with various information that aided in producing this report. The faculty members and students of my laboratory helped to arrange and analyze the data. In particular, I would like to thank the students who stayed in Sendai during the accident and helped us as a contribution to society, instead of going to volunteer for disaster recovery. I would also like to express my gratitude to Mr. Shuichi Moriya, a technical staff member of my laboratory, for his assistance in preparing the figures.

\section{AbBreviations}

AOV

BAF

BWR boiling water reactor

D/W drywell

HTC Rep. \#, date: Maruyama S., Komiya A., and Okajima J., Heat Transfer Control Laboratory,
Institute of Fluid Science, Tohoku University, Report, 2011-2015

http://www.ifs.tohoku.ac.jp/komiya/maru/atom/i ndex.html

$\mathrm{HPCl}$ high pressure coolant injection system

IAEA International Atomic Energy Agency

IC isolation condenser

MAAP Modular Accident Analysis Program

MOV motor-operated valve

NPP nuclear power plant

NRA Nuclear Regulation Authority of Japan

PCV primary containment vessel

PLR primary loop recirculation system

$\mathrm{R} / \mathrm{B} \quad$ reactor building

$\mathrm{RCIC}$ reactor core isolation cooling system

$\mathrm{RHR}$ residual heat removal system

RPV reactor pressure vessel

S/C suppression chamber (suppression pool)

SRV main steam safety relief valve

STGS standing gas treatment system

SV safety valve

TAF top of active fuel

TC thermocouple

TEPCO Tokyo Electric Power Company

\section{References Références Referencias}

1. National Police Agency of Japan, Police countermeasures and damage situation associated with 2011Tohoku district - off the Pacific Ocean earth quake, February 10, 2021. http://www.npa.go. jp/news/other/earthquake2011/pdf/higaijokyo_e.pdfl

2. Maruyama S., Komiya A., and Okajima J.,Heat Transfer Control Laboratory, Institute of Fluid Science, Tohoku University, Thermal analysis and control plan of the accident of Fukushima Daiichi Nuclear Power Plant, 2011-2015. (in Japanese) http://www.ifs.tohoku.ac.jp/komiya/maru/atom/index .html

3. Tokyo Electric Power Company (TEPCO), Analysis and impact assessment of Fukushima Daiichi Nuclear Power Plant operation records and accident records at the time of the Great East Japan Earthquake, 23 May 2011. (in Japanese) https://www.tepco.co.jp/cc/press/betu11_j/images/1 10524a.pdf

4. Government of Japan, Investigation Committee on the Accident at Fukushima Nuclear Power Stations of Tokyo Electric Power Company, Interim report, 26 December 2011. https://www.cas.go.jp/jp/seisaku/ icanps/eng/interim-report.html

5. International Atomic Energy Agency (IAEA), The Fukushima Daiichi accident, Report by the director general, August 2015. https://www-pub.iaea. org/mtcd/publications/pdf/pub1710-reportbythedgweb.pdf 
6. Tokyo Electric Power Company (TEPCO), Fukushima Nuclear Accident Analysis Report, 20 June 2012.https://www.tepco.co.jp/en/press/corpcom/release/betu12_e/images/120620e0104.pdf

7. Maruyama, S., Heat and fluid flow in accident of Fukushima Daiichi Nuclear Power Plant, Unit 1 When the isolation condenser was working-, Maintenology, Vol.11, No.3, pp. 93-99, 2012. (in Japanese) https://mainte-archive.cloud/006140

8. Maruyama, S., Heat and fluid flow in in accident of Fukushima Daiichi nuclear power plant, Unit 2 (Accident scenario based on thermodynamic model), Transactions of JSME, Series B Vol. 78, No.796, pp. 2127-2141, 2012, (in Japanese). https://www.jstage.jst.go.jp/article/kikaib/78/796/78_ 2127/_pdf/-char/ja

9. Maruyama, S., Heat and fluid flow in accident of Fukushima Daiichi nuclear power plant, Unit 1 (Behavior of isolation condensers (ICs) based on thermodynamic model), Transactions of JSME, Vol. 80, No.820, 2014, (in Japanese). https://www. jstage.jst.go.jp/article/transjsme/80/820/80_2014tep 0377/_pdf/-char/ja

10. Atomic Energy Society of Japan, The Fukushima Daiichi nuclear accident, Final report of the AESJ investigation committee, Springer, 2015, (Originally published in Japanese in March 2014).

11. Nuclear Regulation Authority of Japan, Analysis of the TEPCO Fukushima Daiichi NPS Accident, Interim Report (Provisional Translation), October 2014. https://www.iaea.org/sites/default/files/anayly sis nra1014.pdf

12. Tokyo Electric Power Company (TEPCO), Evaluation of the situation of cores and containment vessels of Fukushima Daiichi Nuclear Power Station Units-1 to 3 and examination into unsolved issues in the accident progression, Progress Report No. 1, 13 December 2013. https://www.tepco.co.jp/en/press/ corp-com/release/betu13_e/images/131213e0102. pdf

13. Tokyo Electric Power Company (TEPCO), Evaluation of the situation of cores and containment vessels of Fukushima Daiichi Nuclear Power Station Units-1 to 3 and examination into unsolved issues in the accident progression, Progress Report No. 2, 6 August 2014.https://www.tepco.co.jp/en/press/corpcom/release/betu14_e/images/140806e0102.pdf

14. Tokyo Electric Power Company (TEPCO), Evaluation of the situation of cores and containment vessels of Fukushima Daiichi Nuclear Power Station Units-1 to 3 and examination into unsolved issues in the accident progression, Progress Report No. 3, 20 May 2015. https://www.tepco.co.jp/en/press/corpcom/release/betu15_e/images/150520e0102.pdf

15. Tokyo Electric Power Company (TEPCO), Evaluation of the situation of cores and containment vessels of Fukushima Daiichi Nuclear Power Station Units-1 to
3 and examination into unsolved issues in the accident progression, Progress Report No. 4, 17 December 2015. https://www.tepco.co.jp/en/press/ corp-com/release/betu15_e/images/151217e0102. pdf

16. Tokyo Electric Power Company (TEPCO), Evaluation of the situation of cores and containment vessels of Fukushima Daiichi Nuclear Power Station Units-1 to 3 and examination into unsolved issues in the accident progression, Progress Report No. 5, 25 December 2017. https://www.tepco.co.jp/en/press/ corp-com/release/betu17_e/images/171225e0201 .pdf

17. Maruyama, S., Heat and fluid flow in accident of Fukushima Daiichi nuclear power plant, Unit 3 Whenthe high-pressure coolant injection system (HPCl) stopped-, Maintenology, Vol.11, No.3, pp. 100-109, 2012. (in Japanese) file:///C:/Users/ maruyama/Downloads/HZN_001_20121001_100_01 .pdf

18. Maruyama, S., Heat and fluid flow in accident of Fukushima Daiichi nuclear power plant, Unit 3 (Behavior of high pressure coolant injection system (HPCl) based on thermodynamic model), Transactions of the JSME, Vol.80, No.814, 2014. (in Japanese)https://www.jstage.jst.go.jp/article/transjs me/80/814/80_2014tep0155/_pdf/-char/ja

19. Nuclear Regulation Authority of Japan, Interim report on investigation and analysis of TEPCO Fukushima Daiichi nuclear power plant accident (draft), 18 December 2020. (in Japanese)

20. Maruyama, S.,FUKUSHIMA; ANovel, Yokendo, August 2012. (in Japanese) ISBN-4842505044

21. Government of Japan, Investigation Committee on the Accident at Fukushima Nuclear Power Stations of Tokyo Electric Power Company, Hearing records, 21 July 2011 - 26 June 2012. (in Japanese) https://www8.cao.go.jp/genshiryoku_bousai/fu_kou kai/fu_koukai_2.html\#a

22. TEPCO, Proposed revision of the medium- and long-term roadmap for decommissioning of the Fukushima Daiichi Nuclear Power Plant, 27 December 2019. (in Japanese) https://www. meti.go.jp/earthquake/nuclear/pdf/20191227.pdf

23. National Diet of Japan, The official report of the Fukushima Nuclear Accident Independent Investigation Commission, 11 March 2012. https:// www.nirs.org/wp-content/uploads/fukushima/naiic_ report.pdf

24. Maruyama, S., Thermal Science for Everyone, Yokendo, 2015. (in Japanese) ISBN978-4-86163272-3

25. Tokyo Electric Power Company (TEPCO), Fukushima Daiichi Nuclear Power Plant, Situation of the response immediately after the disaster, 18 June 2011. (in Japanese) https://www.tepco.co.jp/cc/ press/betu11_j/images/110618l.pdf 
26. Nuclear and Industrial Safety Agency (NISA), Time series data concerning the status of reactors at each unit of Fukushima Daiichi and Fukushima Daini NPPs submitted from TEPCO, June 24, 2011. (in Japanese) https://www.nsr.go.jp/activity/bousai/ trouble/gensai_25/archive_nisa/index.html

27. White, F. M., Fluid Mechanics, McGraw Hill, (1999), p. 397.

28. Liepmann, H .W. and Roshko, A., Elements of Gasdynamics, John Willey \& Sons, (1956), pp53-54.

29. Tokyo Electric Power Company (TEPCO), Temperature data of various measurement points in Unit 1, 17 May 2011.

30. Tokyo Electric Power Company (TEPCO), List of plant data collected by the operator during the accident, 27 November 2011. (in Japanese) https://www.tepco.co.jp/nu/fukushima-np/plantdata/131127_plantdata_01.pdf

38 31. Tokyo Electric Power Company (TEPCO), Fukushima Nuclear Accident Analysis Report, Intermediate Report, Attachment, 2 December 2011. (in Japanese) https://www.tepco.co.jp/decom mission/information/accident_investigation/pdf/1206 20j0306.pdf 